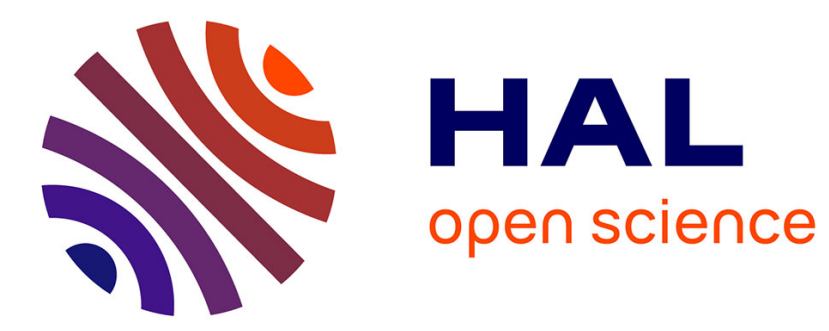

\title{
Trabecular architecture in the humeral metaphyses of non-avian reptiles (Crocodylia, Squamata and Testudines): Lifestyle, allometry and phylogeny
}

Martial Plasse, Eli Amson, Jérémie Bardin, Quentin Grimal, Damien Germain

\section{- To cite this version:}

Martial Plasse, Eli Amson, Jérémie Bardin, Quentin Grimal, Damien Germain. Trabecular architecture in the humeral metaphyses of non-avian reptiles (Crocodylia, Squamata and Testudines): Lifestyle, allometry and phylogeny. Journal of Morphology, 2019, 280 (7), pp.982-998. 10.1002/jmor.20996 . hal-02188785

\section{HAL Id: hal-02188785 \\ https://hal.sorbonne-universite.fr/hal-02188785}

Submitted on 18 Jul 2019

HAL is a multi-disciplinary open access archive for the deposit and dissemination of scientific research documents, whether they are published or not. The documents may come from teaching and research institutions in France or abroad, or from public or private research centers.
L'archive ouverte pluridisciplinaire HAL, est destinée au dépôt et à la diffusion de documents scientifiques de niveau recherche, publiés ou non, émanant des établissements d'enseignement et de recherche français ou étrangers, des laboratoires publics ou privés. 


\title{
Trabecular architecture in the humeral metaphyses of non-avian reptiles (Crocodylia, Squamata and Testudines): Lifestyle, allometry and phylogeny
}

\author{
Martial Plasse $^{1,2}$ (D) | Eli Amson ${ }^{3}$ | Jérémie Bardin ${ }^{4}$ Q Quentin Grimal ${ }^{2}$ | \\ Damien Germain ${ }^{1}$
}

${ }^{1}$ Muséum national d'Histoire naturelle, UMR 7207 - CR2P-CNRS-MNHN-Sorbonne Université, Paris, France

${ }^{2}$ INSERM UMR S 1146, CNRS UMR 7371, Laboratoire d'Imagerie Biomédicale, Sorbonne Université, Paris, France

${ }^{3}$ Museum für Naturkunde, Leibniz-Institut für Evolutions- und Biodiversitatsforschung, Berlin, Germany

${ }^{4}$ UMR 7207 - CR2P-CNRS-MNHN- Sorbonne Université, Université Pierre et Marie Curie, Paris Cedex 05, France

\section{Correspondence}

Martial Plasse, UMR 7207 - CR2P-CNRSMNHN-Sorbonne Université, Muséum national d'Histoire naturelle, 43 rue Buffon, 75005 Paris, France.

Email: martial.plasse@mnhn.fr

Funding information

Muséum National d'Histoire Naturelle; Université Pierre et Marie Curie; German Research Council

\begin{abstract}
The lifestyle of extinct tetrapods is often difficult to assess when clear morphological adaptations such as swimming paddles are absent. According to the hypothesis of bone functional adaptation, the architecture of trabecular bone adapts sensitively to physiological loadings. Previous studies have already shown a clear relation between trabecular architecture and locomotor behavior, mainly in mammals and birds. However, a link between trabecular architecture and lifestyle has rarely been examined. Here, we analyzed trabecular architecture of different clades of reptiles characterized by a wide range of lifestyles (aquatic, amphibious, generalist terrestrial, fossorial, and climbing). Humeri of squamates, turtles, and crocodylians have been scanned with microcomputed tomography. We selected spherical volumes of interest centered in the proximal metaphyses and measured trabecular spacing, thickness and number, degree of anisotropy, average branch length, bone volume fraction, bone surface density, and connectivity density. Only bone volume fraction showed a significant phylogenetic signal and its significant difference between squamates and other reptiles could be linked to their physiologies. We found negative allometric relationships for trabecular thickness and spacing, positive allometries for connectivity density and trabecular number and no dependence with size for degree of anisotropy and bone volume fraction. The different lifestyles are well separated in the morphological space using linear discriminant analyses, but a cross-validation procedure indicated a limited predictive ability of the model. The trabecular bone anisotropy has shown a gradient in turtles and in squamates: higher values in amphibious than terrestrial taxa. These allometric scalings, previously emphasized in mammals and birds, seem to be valid for all amniotes. Discriminant analysis has offered, to some extent, a distinction of lifestyles, which however remains difficult to strictly discriminate. Trabecular architecture seems to be a promising tool to infer lifestyle of extinct tetrapods, especially those involved in the terrestrialization.
\end{abstract}

\section{KEYWORDS}

bone functional adaptation, bone volume fraction, degree of anisotropy, epiphysation, histology 


\section{1 | INTRODUCTION}

Bone is a tissue able to adapt to its external mechanical environment. This seminal insight, commonly referred to as "bone functional adaptation," has been originally described by Wilhelm Roux (Roux, 1885). Within the bones, trabecular architecture is more responsive and malleable to external loads (for a review see Cowin, 1998, Kivell, 2016). During bone modeling, osteocytes embedded in the bone matrix act as mechano-sensors and send strain-related signals to other cells (Huiskes, Ruimerman, Van Lenthe, \& Janssen, 2000). They recruit osteoblasts, which create bone, and osteoclasts, which resorb bone (Gerhard, Webster, Van Lenthe, \& Müller, 2009), processes which result in bone functional adaptation (Martin, Burr, Sharkey, \& Fyhrie, 2015).

A change of loading regimes on bone can modify the trabecular architecture. Many experimental studies support this hypothesis. For instance, macaques trained to walk bipedally have shown significantly different shape of femur and ilium than wild (quadrupedal) ones (Volpato, Viola, Nakatsukasa, Bondioli, \& Macchiarelli, 2008). Therefore, different locomotor behaviors may leave different signatures inside bones. Indeed, in the above-cited bipedally trained macaque, the trabecular architecture of the iliac body became more anisotropic, thicker, and more structured vertically oriented (Volpato et al., 2008). In the same way, sheep exercised daily to trot on inclined treadmills have developed thicker trabeculae with a higher bone volume fraction in their distal radius (Barak, Lieberman, \& Hublin, 2011). A similar adaptation in trabecular architecture has been shown in rabbits by the application of in vivo cyclic loading on the hind limbs (van der Meulen et al., 2006).

Many studies have attempted to test for correlations between trabecular architecture and locomotor behavior. In primates, trabecular architecture can be different in the femoral head according to the locomotor behavior: between leaping and nonleaping strepsirrhines (Ryan \& Ketcham, 2002a), among locomotor behaviors (quadruped, climber, biped, quadrumanous, brachiator) of anthropoids (Ryan \& Shaw, 2012), between hunter-gatherer populations and agricultural societies (Ryan \& Shaw, 2014). In contrast, other studies found that trabecular structures are highly similar among the proximal femoral necks of anthropoid locomotor behaviors, but also between their humeral and femoral head (Fajardo, Müller, Ketcham, \& Colbert, 2007; Ryan \& Walker, 2010). Other studies, focused on extant primates, have attempted to infer the locomotor behavior of extinct primates, for example, omomyids (Ryan \& Ketcham, 2002b) or Australopithecus (Barak et al., 2013).

Lifestyle represents the environment where the animal usually lives (e.g., terrestrial, fossorial, climber, aquatic or amphibious). Many lifestyles can be encompassed by a same locomotor behavior and vice versa. For instance, species walking quadrupedally can have various lifestyles such as on land (terrestrial), underground (fossorial), in trees (climber) or at the bottom of lakes (aquatic/amphibious). In contrast to locomotor behavior, the link between trabecular architecture and lifestyle has been little studied and research in this field is scarce. In an analysis focused on the humeral and femoral head of four primates species, terrestrial taxa have shown more anisotropic trabecular architecture in comparison to arboreal ones (Fajardo \& Müller, 2001). In another broader study on anthropoid primates, trabecular architecture from the humeral and femoral heads was found to be similar in arboreal and terrestrial locomotor groups (Ryan \& Shaw, 2012). In a study focused on the fore limb epiphyses of xenarthrans, trabeculae have shown the clearest functional signal through their anisotropy: armadillos, fully terrestrial and fossorial, have the most anisotropic trabecular architecture in xenarthrans (Amson, Arnold, van Heteren, Canoville, \& Nyakatura, 2017). In a study focused on the sciuromorph femoral head, four trabecular parameters have shown functional signals related to the various lifestyles found in this clade (Mielke et al., 2018).

Thanks to the development of X-ray computed microtomography, 3D trabecular architecture could be extensively studied in birds (e.g., Bishop et al., 2018; Doube, Kłosowski, Wiktorowicz-Conroy, Hutchinson, \& Shefelbine, 2011; Fajardo, Hernandez, \& O'Connor, 2007; Pontzer et al., 2006) and mammals (e.g., many orders [Doube et al., 2011], bovids [Mittra, Rubin, \& Qin, 2005, Sode, Burghardt, Nissenson, \& Majumdar, 2008], lagomorphs [Marchand, Chen, Buschmann, \& Hoemann, 2011, van der Meulen et al., 2006], primates [Barak, Lieberman, Raichlen, et al., 2013, Cunningham \& Black, 2009, Kivell, Skinner, Lazenby, \& Hublin, 2011, Lazenby, Skinner, Kivell, \& Hublin, 2011, Sode et al., 2008], rodents [Carlson, Lublinsky, \& Judex, 2008, Lambers et al., 2013, Sode et al., 2008], sciuromorphs [Mielke et al., 2018], suids [Ben-Zvi, Reznikov, Shahar, \& Weiner, 2017], and xenarthrans [Amson et al., 2017]). In comparison, 3D trabecular architecture of nonavian reptiles has received little attention. The extensive sampling of Doube et al. (2011) includes a single femur of Crocodylus niloticus. Recently, another study focused on the trabeculae of avian hind limb bones (femur, tibia, tibiotarsus, and fibula) to infer dinosaurian locomotion and these observations were compared to those made on crocodylians and lizards, that is, two species of Crocodylus and three of Varanus (Bishop et al., 2018). One should note that the latter study only analyzed trabecular direction. Thus, few data exist about taxa using a sprawling posture.

The purpose of this article is to highlight relations between humeral trabecular architecture and lifestyle within various clades of reptiles (Crocodylia, Squamata, and Testudines). These groups exhibit a broad variability of lifestyles: aquatic, amphibious, generalist terrestrial, fossorial, or climbing. According to the paradigm of the bone functional adaptation, we predict: a terrestrial tetrapod will show trabeculae with a well-marked main orientation (mainly subject to gravity), while an aquatic tetrapod will show a more isotropic trabecular architecture (the gravity effect being strongly decreased). For an amphibious tetrapod, we expect its trabecular structure to be intermediate in that regard. A similar interpretation has allowed the inference that the stem-tetrapod Ossinodus spent considerable time on land, on the basis of essentially parallel trabeculae in its radius (Bishop et al., 2015). Our expectations are herein tested in statistical framework taking into account both allometric and phylogenetic effects. 


\section{2 | MATERIAL AND METHODS}

\section{1 | Specimens and functional categories}

The humerus was selected for this study for several reasons. While the hind limb has been completely reduced in various taxa, for example, in Bipes biporus (Amphisbaenia), the fore limb is more commonly retained. Also, during tetrapod evolution, the fore $\operatorname{limb}$ is hypothesized to have been the first to gain a role in land/substrate locomotion, as suggested for Ichthyostega (Pierce, Clack, \& Hutchinson, 2012). The hind limb exapted only later in the evolution of the clade to walk on land. We sampled 10 squamates, eight turtles and two crocodylians (Table 1). Ideally, we tried to encompass most of the reptilian diversity choosing one specimen per family among the most disparate ones (except for the two species of the genus Varanus). All sampled specimens of squamates still possess an epiphyseal plate, except for Tiliqua, which ended its growth. Turtles and crocodylians do not develop epiphyseal plates. The specimen MNHN-ZA-AC1889-384, from Gabon, belongs to the species Trionyx cryptopus, which is not valid anymore. It could be Cyclanorbis senegalensis (=Cryptopus senegalensis Dumeril \& Bibron, 1835), which is not reported in Gabon for the moment (S. Bailon, pers. comm.).

We selected species in order to cover a broad spectrum of lifestyles: aquatic, amphibious, generalist terrestrial, fossorial and climber. Lifestyle is difficult to assess, because it is a somewhat continuous variable. We defined as terrestrial a species that generally lives on the ground, although it might be able to occasionally dig underground or climb. A climbing species will be found most of the time on plants (arboreal) or on rocks (saxicolous). A fossorial species is able to dig burrows with claws or with the head. An amphibious species spends a considerable amount of time both on the ground and in the water. An aquatic species spends most its time in water and can show special aquatic adaptations such as swimming paddles. Lifestyle for each taxon with associated bibliographic references is given in Table 1. Within reptiles, similar lifestyles have been acquired many times independently (Figure 1). Squamates are mainly terrestrial, but fossorial and climbing lifestyles appear to have been convergently acquired on several instances (see Figure 1). Amblyrhynchus is the only sampled amphibious taxon among extant squamates. Sampled crocodylians are only amphibious. Testudines are mainly amphibious, but the aquatic lifestyle was convergently acquired in Chelus and Caretta. Centrochelys is the only fossorial turtle in our sampling. Therefore, the sampled phylogeny and lifestyles do not perfectly correlate. Nevertheless, a two-block partial least squares analysis (Adams \& Collyer, 2018) suggests that the lifestyles groups are aggregated on the phylogeny (Figure 1) to some extent (r-PLS: 0.7224; $p$-value: .0162, see script in Supporting Information, file 1).

In addition to lifestyles, we also took into account locomotor postures (and associated bibliographic references, Table 1), which have already been correlated to the trabecular architecture. Extant tetrapods show two main types of limb posture: a "sprawling" posture in salamanders and lizards, in which the limbs project laterally from the body and an "erect" posture in mammals and birds, in which the limbs are held under the body (Russell \& Bels, 2001). Extant crocodylians are generally defined as semi-erect with the body held halfway between the positions of the two other limbs postures (Reilly \& Elias, 1998). Squamates can show two "sprawling" postures: a "belly-dragging" sprawling posture (e.g., Tiliqua scincoides) in which the animal's weight partially rests on the trunk with a direct contact to the substrate or a "raised" sprawling posture (e.g., Iguana iguana) without ventral trunk-ground contact and in which the shoulder/hip and elbow/knee joints bear the animal's weight (Nyakatura et al., 2014). We also noted when the species is able to practice bipedalism, either involved in an escape behavior (e.g., Basiliscus) or in defensive posturing (e.g., many species of Varanus). In turtles, we distinguished two groups according to the locomotor preference: the "bottom-walkers" and the "good swimmers." Thus, inside the same locomotor behavior (e.g., quadrupedal locomotor behavior), many locomotor postures can be observed among tetrapods ("belly-dragging" sprawling, "raised" sprawling, or "erect" postures). Each clade of reptiles is characterized by its own locomotor postures (Figure 1). Squamates are all sprawlers, but belly dragging sprawling posture and/or raised sprawling posture were convergently acquired several times, which is also the case for occasional bipedalism. Testudines are either bottom walkers or good swimmers, but at least one of these postures appeared twice independently. As for lifestyles, postures do not perfectly aggregate on the phylogeny (Figure 1), but there is nevertheless a correlation ( $r$-PLS: $0.8375, p$-value: .001, see script in Supporting Information, file 1).

\section{2 | Data acquisition}

Left or right humeri, depending on the availability, were X-rayed using a computed tomography (CT) imaging system (AST-RX platform and Ge Sensing and inspection Technologies phoenix-ray $v \mid$ tome|x L240-180 CT scanner) at the Muséum national d'Histoire naturelle (MNHN), with nanofocus RX source $180 \mathrm{kV} / 15 \mathrm{~W}$ and detector $400 \times 400 \mathrm{~mm}$ with a matrix of 2,024 pixels (pixel size: $200 \times$ $200 \mu \mathrm{m})$. The images were acquired with different scan parameters (exposure time, voltage, current and filter; see Supporting Information, file 2) according to the specimens and the voxel sizes ranged from 13.604 to $113.825 \mu \mathrm{m}$. The micro-CT data were processed utilizing datos $\mid x$ reconstruction software (Phoenix $\mid x$-ray, release 2.0) and then exported as a 16 bits TIFF image stack.

Volumes of interest (VOIs) were selected with the software CTAnalyser (CTAnalyser Software V 1.16, Skyscan NV, Kontich, Belgium). We chose spherical VOls centered in the proximal metaphysis, at the location where the pectoral process is the most developed, because this part is present across the whole dataset (Figure 2). We defined the VOls to be as large as possible to sample as many trabeculae as possible, but without including cortical bone. This trabecular extraction was preferred to other traditional methods (same size VOls or VOls proportional to the epiphysis size) to obtain a maximum of trabeculae from small specimens. The rest of the process was performed with the Fiji package (Schindelin et al., 2012) and the BoneJ plugin (Doube et al., 2010). The extracted VOls were binarized with 


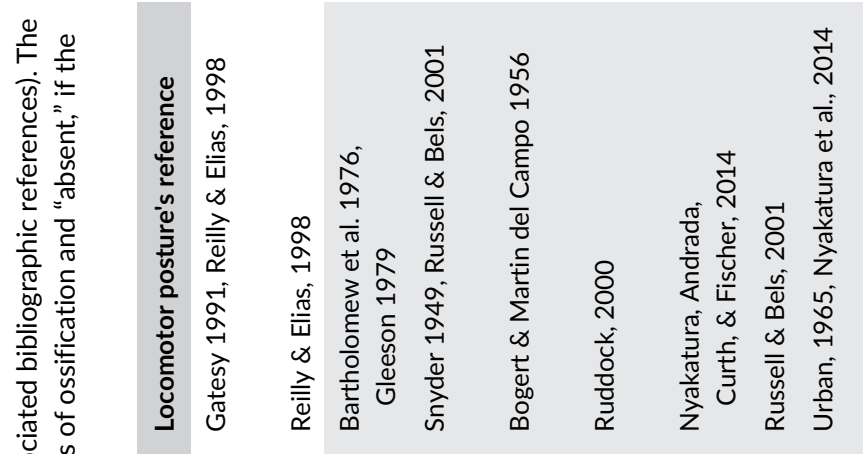

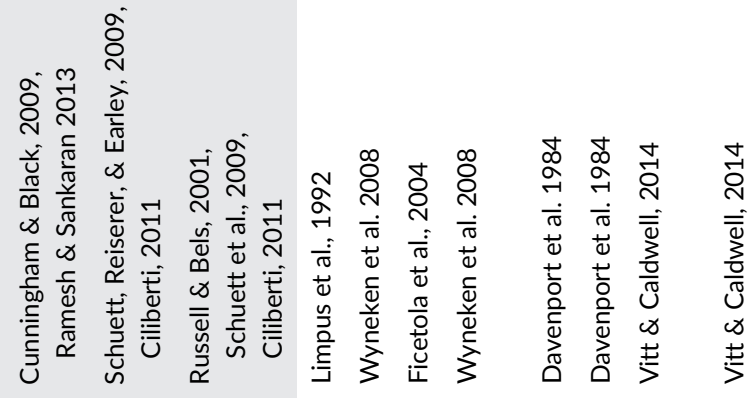

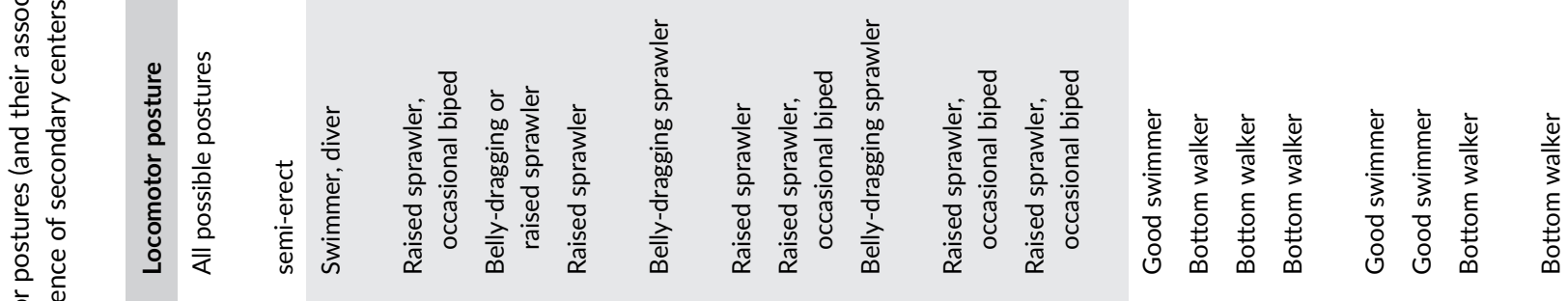

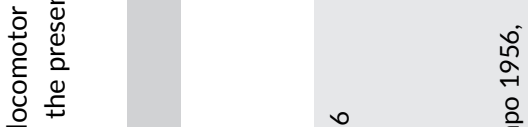

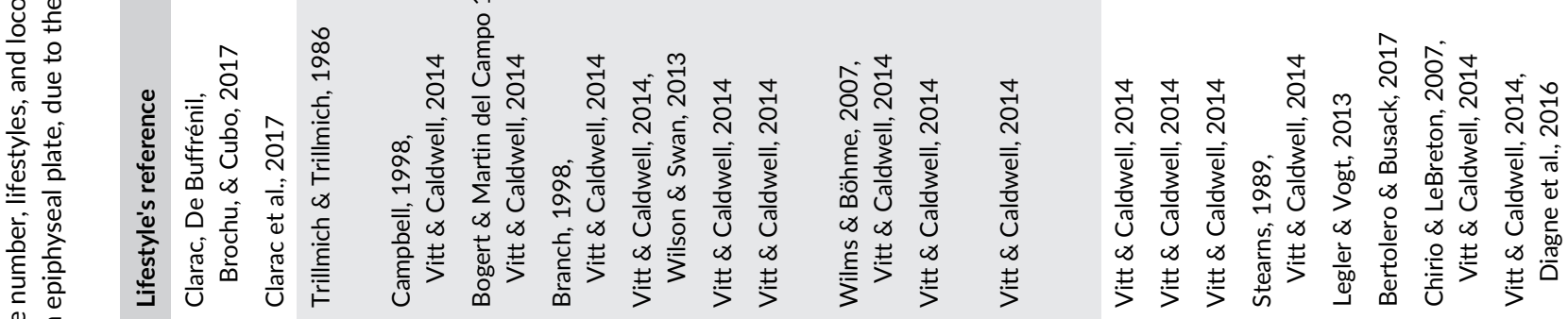

(1)

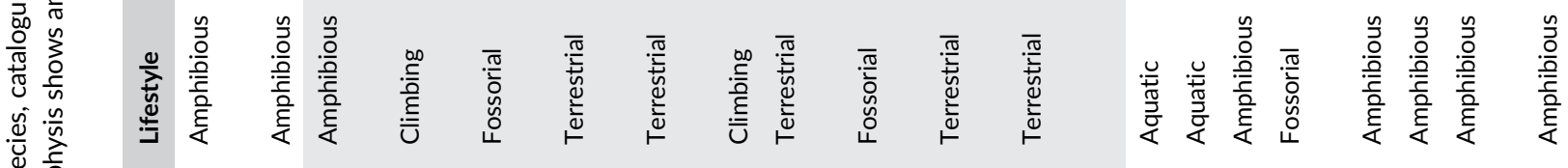

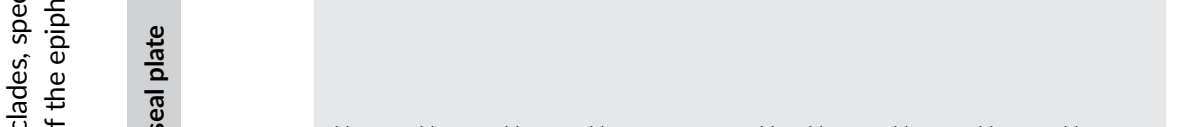

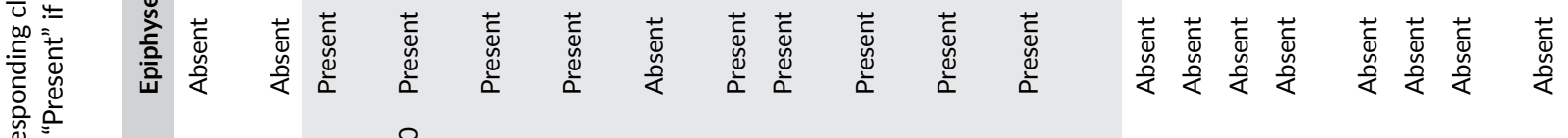

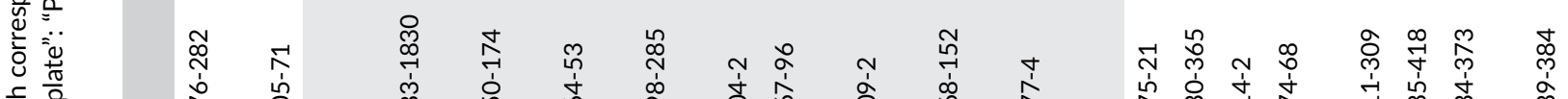

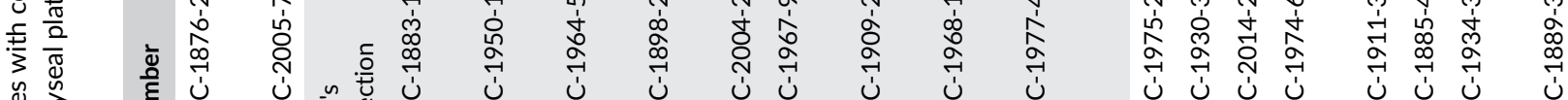

峁 竞

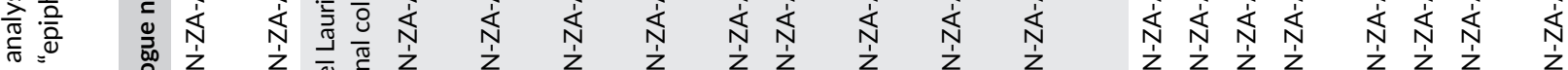

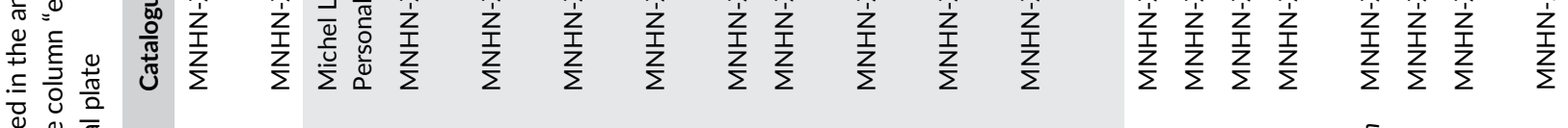

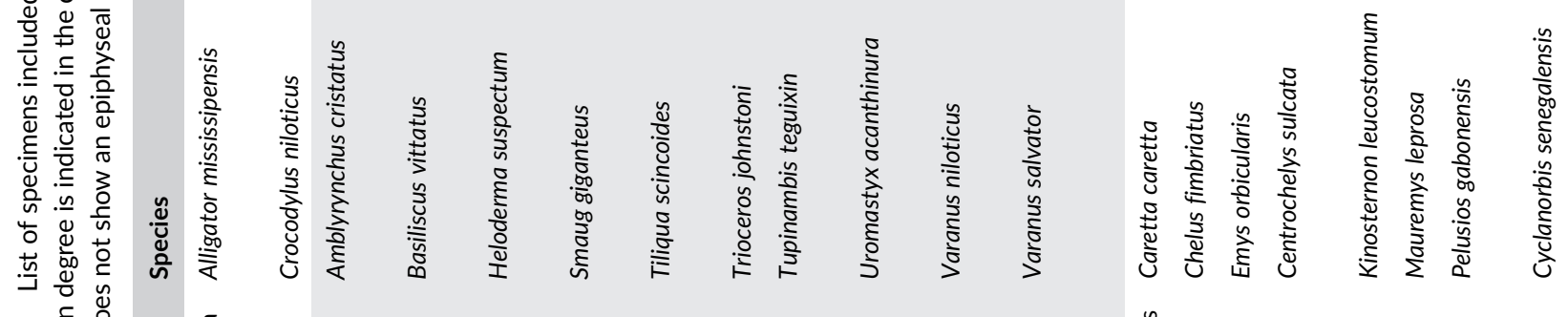

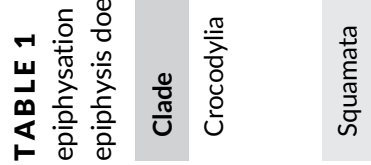




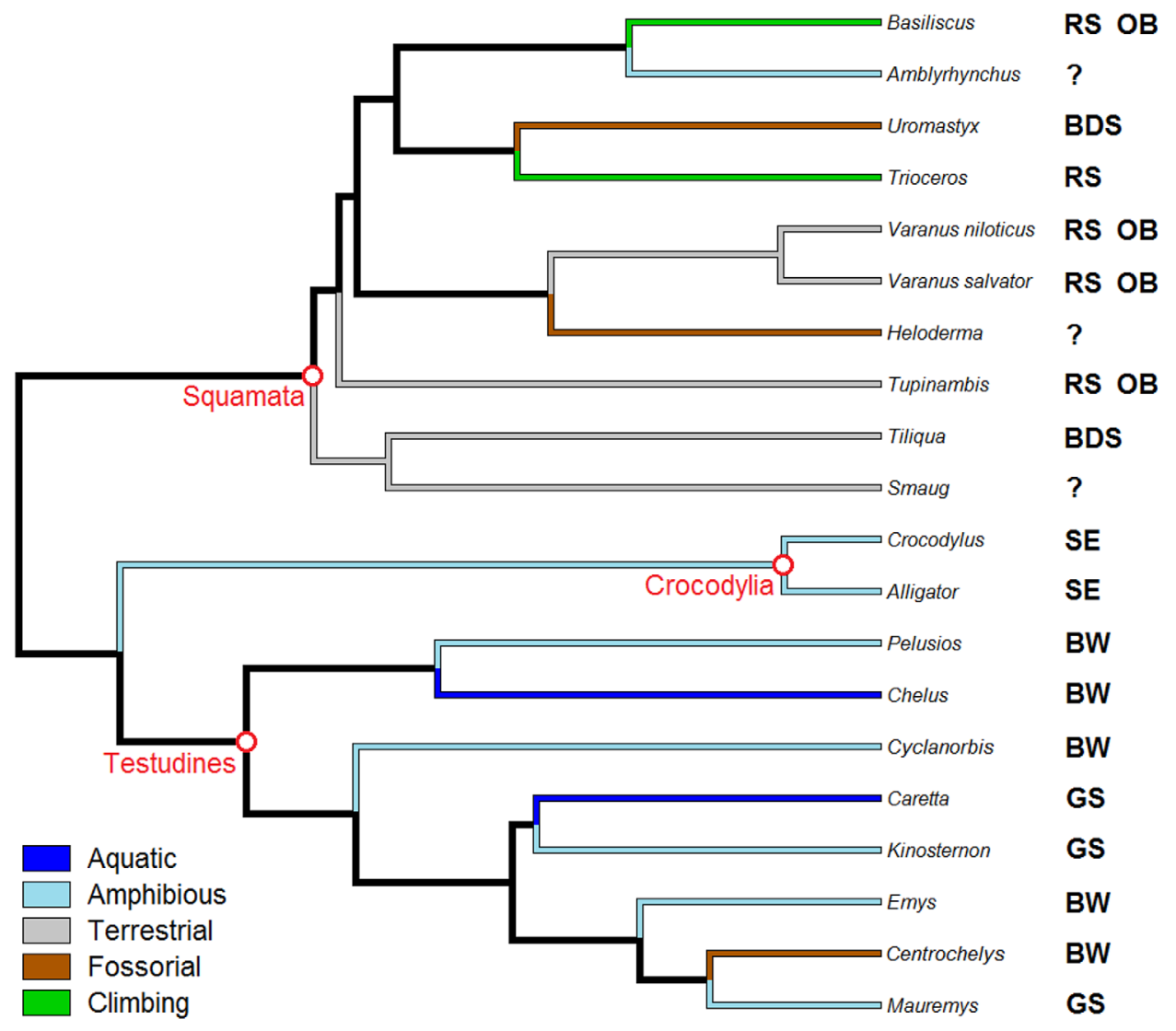

FIGURE 1 Phylogeny of studied specimens, modified from Zheng and Wiens (2016) and Shaffer, McCartney-Melstad, Near, Mount, and Spinks (2017). Color represents the different lifestyles. Locomotor postures are indicated on the right. A question mark indicates an unclear posture. BDS, belly-dragging sprawler; BW, bottom walker; GS, good swimmer; OB, occasional biped; RS, raised sprawler; $\mathrm{SE}$, semi-erect [Color figure can be viewed at wileyonlinelibrary.com]

"Optimize Threshold > Threshold Only" and their isolated particles was removed with "Purify."

Then eight trabecular parameters were measured with BoneJ (raw measurements given in Table 2, means for each lifestyle in Table 3, for Squamata and Testudines in Table 4, see Fiji Macro in Supporting Information, file 3). These parameters were often used by others authors, except for average branch length (Av.Br.Len, only measured by Amson et al., 2017). Thickness (Tb.Th) and Av.Br.Len are expressed in mm; bone surface (BS) in $\mathrm{mm}^{2}$; bone volume (BV) in $\mathrm{mm}^{3}$; connectivity (Conn) is approximately the number of trabeculae in the VOI; connectivity density (Conn.D) in number $/ \mathrm{mm}^{3}$; number (Tb.N) in number/mm. Degree of anisotropy (DA) has no unit, its scale ranges from 0 (trabeculae have no preferential orientation) to 1 (trabeculae are perfectly aligned). As the DA algorithm is a heuristic, we ran it 10 times for each VOI and averaged the obtained values. Two other trabecular parameters, spacing (Tb.Sp) in mm and the total volume of VOI (TV) in $\mathrm{mm}^{3}$, could not be correctly measured from a spherical VOI by BoneJ, which requires a cuboid stack (the option "use ROI Manager" was not used). We therefore devised a custom script to calculated them. After VOI extraction with CTAn and thresholding with BoneJ, we obtained a spherical VOI of trabecular bone (bone in white, void in black) inside a cubic stack with black background. If one would measure Tb.Sp of this stack with BoneJ, the plugin would also consider the spacing between the sphere and the cube vertices. This external space was excluded from the calculation to measure a reliable value of Tb.Sp (Table 2). In the same way, BoneJ will calculate TV from the cubic stack and not from the spherical VOI. Thus, we calculated the spherical TV from its radius $r$ (its diameter can be extracted with CTAn).

Body mass could not have been used as a body size proxy, as it was unknown for all specimens. The average body weight was also unknown for the great majority of the sampled species. Doube et al. (2011) used femoral head radius for that purpose. In our dataset, the shape of humeral head varies greatly among the main clades: in articular view, it is subrectangular in Crocodylia, subovate in Squamata, and subcircular in Testudines. Defining a size proxy with an external measure would therefore be unreliable with such a diversity of humeral shapes. We hence favored TV as a body size proxy, which is directly measured on the specimens.

\section{3 | Statistical analyses}

All the computations were performed with $\mathrm{R}$ version 3.4.4 ( $\mathrm{R}$ Core Team, 2013). The eight following trabecular parameters were included in the analyses: Av.Br.Len, Tb.Th, Tb.Sp, BS/TV, BV/TV, Conn.D, DA, and Tb.N. We calculated size-corrected trabecular parameters, which are the residuals of linear regressions (Im function) of the original parameters against the size proxy TV (in this case, the "size-corrected" parameter name is preceded by "sc"). We performed various comparisons among these parameters depending on lifestyles or locomotor postures. We checked the normality of the distribution (shapiro. test function) and the homogeneity of variance (bartlett. test function). If these conditions were met, we perform a traditional analysis of 

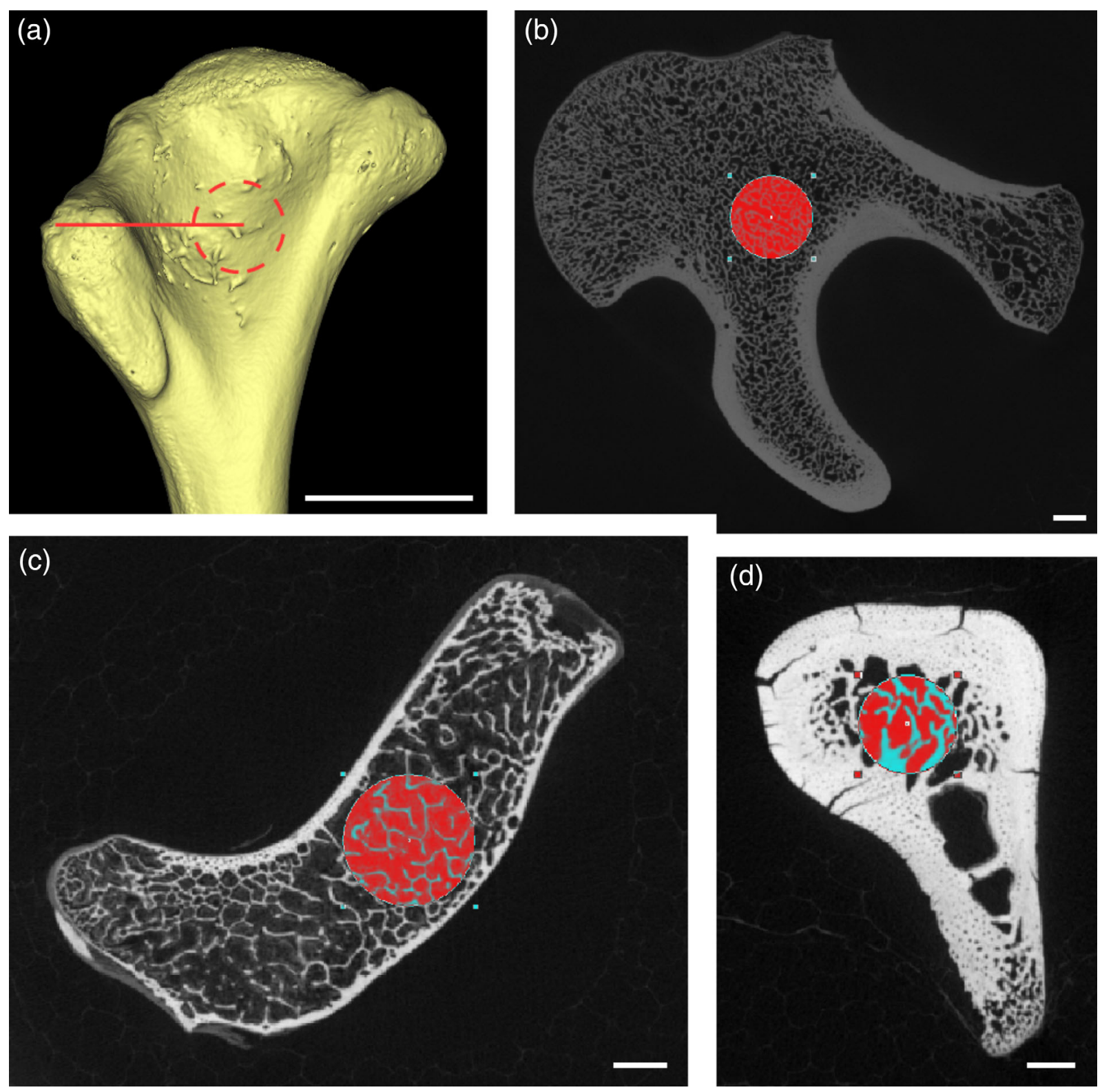

FIGURE 2 Selection of volume of interest (VOI). (a) 3D reconstruction (ventral view) of the proximal epiphysis and metaphysis of the humerus of Tiliqua scincoides (MNHN-ZA-AC-1898-285). (b, $c$ and d) transverse sections in the proximal metaphysis of humerus of Centrochelys sulcata (MNHN-ZA-AC-1974-68), Varanus salvator (MNHN-ZA-AC-1977-4) and Crocodylus niloticus (MNHN-ZA-AC-2005-71), respectively. The red circle represents the place of extraction of $\mathrm{VOI}$, at the location where the pectoral process is the most developed. Scale bars $=2 \mathrm{~mm}[\mathrm{Color}$ figure can be viewed at wileyonlinelibrary.com]

variance (ANOVA, aov function) for a comparison of more than two lifestyles (followed by a Tukey's honestly significant test, TukeyHSD function) or a Student's $t$-test (t.test function) for pairwise comparisons. If at least one of these conditions were missing, we performed a Kruskal-Wallis rank sum test (kruskal.test function) to compare population medians.

Phylogeny: To test whether phylogeny influences the trabecular architecture, we used the Testudines phylogenetic tree topology and the divergence times from Shaffer et al. (2017) and data from Zheng and Wiens (2016) for Crocodylia and Squamata. To measure the phylogenetic signal of each trabecular parameter, we calculated Pagel's lambda (Pagel, 1999, Table 5), with the phylosig function of the "phytools" package (Revell, 2012). The parameter $\lambda$ is a measure of the terminal taxa covariance compared to the covariance expected under a Brownian motion given the topology and the branch lengths. A value of 0 means the phylogenetic independence of the terminal taxa, while a value of 1 means that the values are in direct proportion to their shared evolutionary history. With the contMap and phenogram functions of the "phytools" package (Revell, 2012), we represented the evolution of the BV/TV continuous trait on the tree of reptiles (see mapping in Supporting Information, file 4). Distribution of this trait is also represented with phenograms for squamates (Figure 3) and turtles (Figure 4).

Structural scaling of trabeculae: All variables were log-transformed and allometry was investigated with linear regression of each parameter against the body size proxy, TV. In Mielke et al. (2018), the 


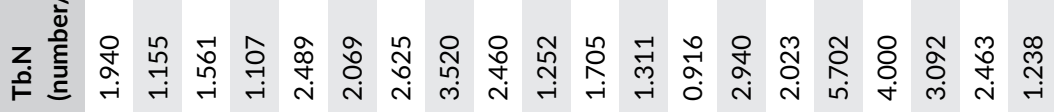

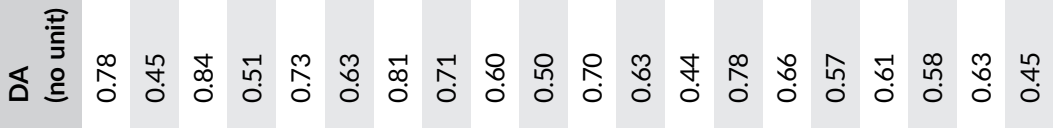

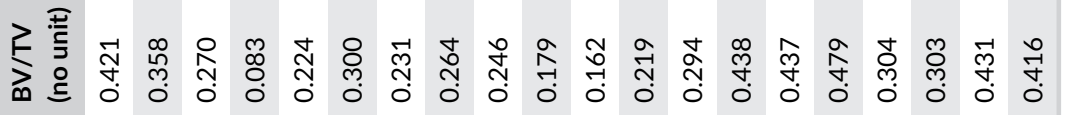

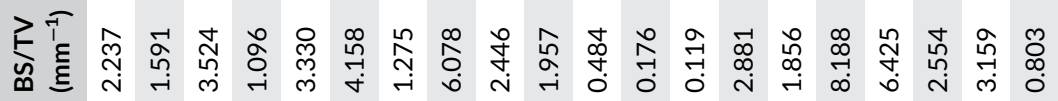

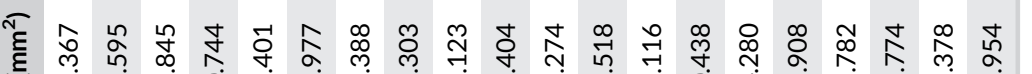

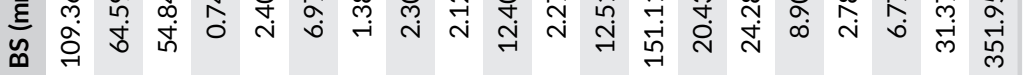

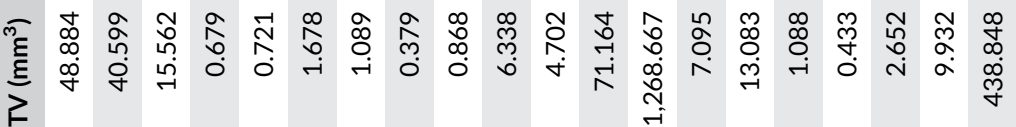

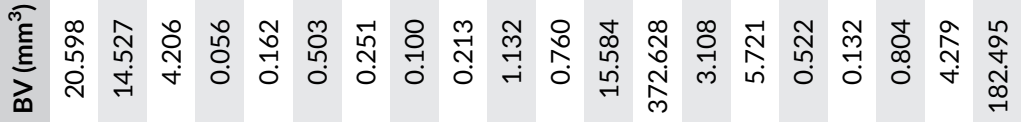

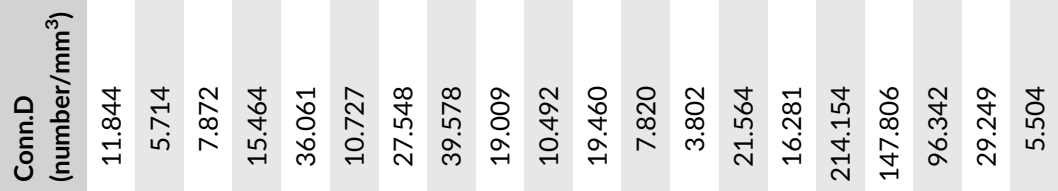

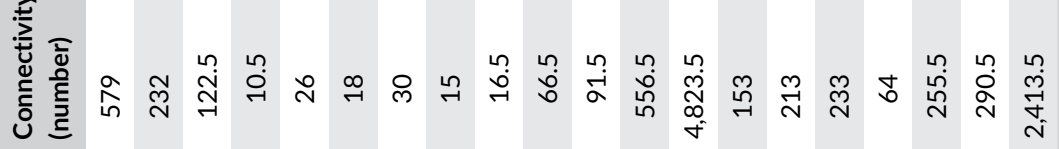

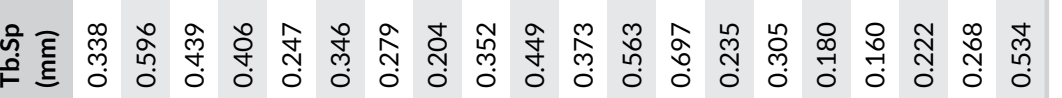

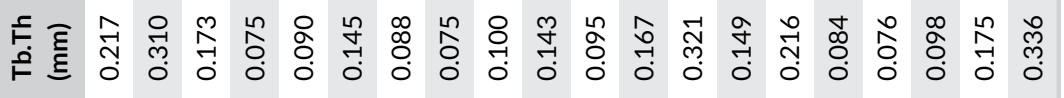

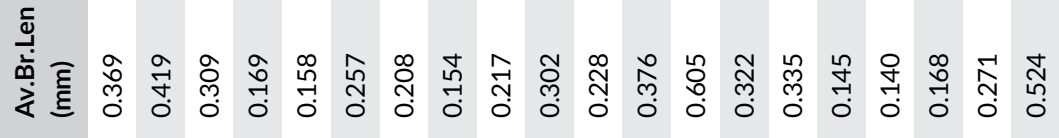

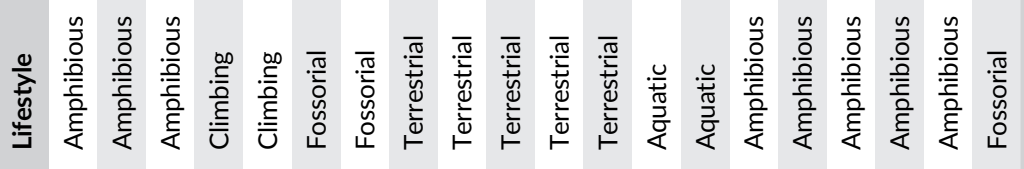


TABLE 3 Means of raw measurements for each lifestyle

\begin{tabular}{|c|c|c|c|c|c|c|c|c|}
\hline Lifestyle & Av.Br.Len (mm) & Tb.Th (mm) & Tb.Sp (mm) & Conn.D (number $/ \mathrm{mm}^{3}$ ) & $\mathrm{BS} / \mathrm{TV}\left(\mathrm{mm}^{-1}\right)$ & BV/TV (no unit) & DA (no unit) & Tb. $\mathrm{N}\left(\mathrm{mm}^{-1}\right)$ \\
\hline Aquatic & 0.463 & 0.235 & 0.466 & 13 & 1.50 & 0.37 & 0.61 & 1.93 \\
\hline Amphibious & 0.270 & 0.169 & 0.313 & 66 & 3.69 & 0.38 & 0.64 & 2.74 \\
\hline Fossorial & 0.330 & 0.190 & 0.386 & 15 & 2.08 & 0.32 & 0.63 & 1.98 \\
\hline Climbing & 0.163 & 0.083 & 0.326 & 26 & 2.21 & 0.15 & 0.62 & 1.80 \\
\hline
\end{tabular}

Note: See Table 2 for abbreviations.

TAB LE 4 Means of raw measurements in Squamata and in Testudines (standard deviation in brackets)

\begin{tabular}{|c|c|c|c|c|c|c|c|c|}
\hline Clade & $\begin{array}{l}\text { Av.Br.Len } \\
(\mathrm{mm})\end{array}$ & Tb.Th (mm) & Tb.Sp (mm) & $\begin{array}{l}\text { Conn.D } \\
\text { (number } / \mathrm{mm}^{3} \text { ) }\end{array}$ & $\begin{array}{l}\mathrm{BS} / \mathrm{TV} \\
\left(\mathrm{mm}^{-1}\right)\end{array}$ & $\begin{array}{l}\text { BV/TV } \\
\text { (no unit) }\end{array}$ & $\begin{array}{l}\text { DA } \\
\text { (no unit) }\end{array}$ & $\begin{array}{l}\text { Tb.N } \\
\left(\mathrm{mm}^{-1}\right)\end{array}$ \\
\hline Squamata & $0.238(0.073)$ & $0.115(0.038)$ & $0.366(0.106)$ & 19 (11.5) & $2.45(1.84)$ & $0.22(0.06)$ & $0.66(0.11)$ & $2.0(0.76)$ \\
\hline
\end{tabular}

Note: See Table 2 for abbreviations.

TAB LE 5 Pagel's lambda and associated $p$-values for each trabecular parameter

\begin{tabular}{|lll|}
\hline & Pagel's lambda & Lambda $p$-value \\
\hline Av.Br.Len & 0.000 & 1.000 \\
\hline Tb.Th & 0.140 & 0.524 \\
\hline Tb.Sp & 0.000 & 1.000 \\
\hline BS/TV & 0.000 & 1.000 \\
\hline Conn.D & 0.166 & 0.486 \\
\hline BV/TV & 0.705 & 0.003 \\
\hline DA & 0.001 & 0.996 \\
\hline Tb.N & 0.000 & 1.000 \\
\hline
\end{tabular}

Note: See Table 2 for abbreviations.

Significant results are in bold ( $p$-value $<.05)$.

observed scaling $\left(a_{\text {obs }}\right)$ of the regression between each trabecular parameter and VOI edge length (both log-transformed) was compared with an expected scaling under isometry $\left(a_{\text {iso }}\right)$. As TV is a volume (unit: $\mathrm{mm}^{3}$ ), the $a_{\text {iso }}$ in our analysis will be equal to the third of values from Mielke et al. (2018), because its VOI edge length was expressed in $\mathrm{mm}$. BV/TV and DA are dimensionless ratios for which $a_{\text {iso }}=0$ (see Table 6, Supporting Information, file 5). Av.Br.Len, Tb.Th, and Tb.Sp are expressed in $\mathrm{mm}$ (unit: length ${ }^{1}$ ) and would increase under isometry with $a_{\text {iso }}=1 / 3$ (length divided by volume). BS/TV (a surface divided by a volume) and Tb.N (a number divided by a length) are expressed in $\mathrm{mm}^{-1}$ and will have an $a_{\text {iso }}=-1 / 3$. Conn.D, expressed in number per $\mathrm{mm}^{3}$ (unit: length ${ }^{-3}$ ), will have an $a_{\text {iso }}=-1$. For each regression, we calculated the confidence intervals to $95 \%$ (confint function) of the observed slope $\left(a_{\text {obs }}\right)$ to test a possible significant deviation between both scalings. An $a_{\text {iso }}$ significantly lower than $a_{\text {obs }}$ and absent from the $a_{\text {obs }}$ confidence intervals indicates positive allometry. An $a_{\text {iso }}$ significantly higher than $\mathrm{a}_{\mathrm{obs}}$ and absent from the $a_{\text {obs }}$ confidence intervals indicates negative allometry. An $a_{\text {obs }}$ nonsignificantly different to $a_{\text {iso }}$ (i.e., $a_{\text {iso }}$ in the $a_{\text {obs }}$ confidence intervals) indicates an isometry.

Lifestyles: We used the "Ida" function (Venables \& Ripley, 2002) from the MASS package to perform several linear discriminant analyses to obtain the best discrimination of various lifestyles. A linear discriminant analysis (LDA) maximizes the variance between groups and minimizes the variance inside each group. We used a leave-oneout cross-validation (CV) to determine the posterior probability for each taxon to belong to a functional group: each specimen is successively removed, then both the model and the prediction for this specific specimen are calculated. We chose to run the LDA according to different modalities (see Table 7, Supporting Information, files 6 and 8): with the raw data or with the size-corrected parameters (to investigate the influence of size in the discrimination) and with or without CV (to compare the predictive ability of the model and the discrimination within the morphological space). In each modality, we calculated the percentage of well-predicted lifestyles, which fit to the number of well-classified specimens divided by the number of specimens. In a first LDA (referred to as "basic"), we used the eight trabecular parameters and the five different lifestyles (aquatic, amphibious, terrestrial, fossorial, and climbing). To investigate the effect of BV/TV, which showed a significant phylogenetic signal (see Table 5), we chose to remove this parameter from a second one. We a priori performed linear correlations between trabecular parameters and we found that BS/TV was highly correlated to Conn.D and Tb.N $\left(R^{2}=.5957, p\right.$ value $=6.72 \times 10^{-5}$, and $R^{2}=.7542, p$-value $=6.88 .10^{-7}$, respectively) and Tb.Sp was highly correlated to Av.Br.Len and Tb.Th $\left(R^{2}=.6891, p\right.$-value $=5.93 .10^{-6}$, and $R^{2}=.561, p$-value $=1.45 .10^{-4}$, respectively). To exclude highly correlated variables, we deleted BS/TV and Tb.Sp in a third one. For the fourth LDA, we performed a principal component analysis (PCA) with the function PCA from the package FactoMineR (Lê, Josse, \& Husson, 2008) and used the extracted scores for the individuals, always in the purpose to obtain a better discrimination with a minimum of variables. Three lifestyles 


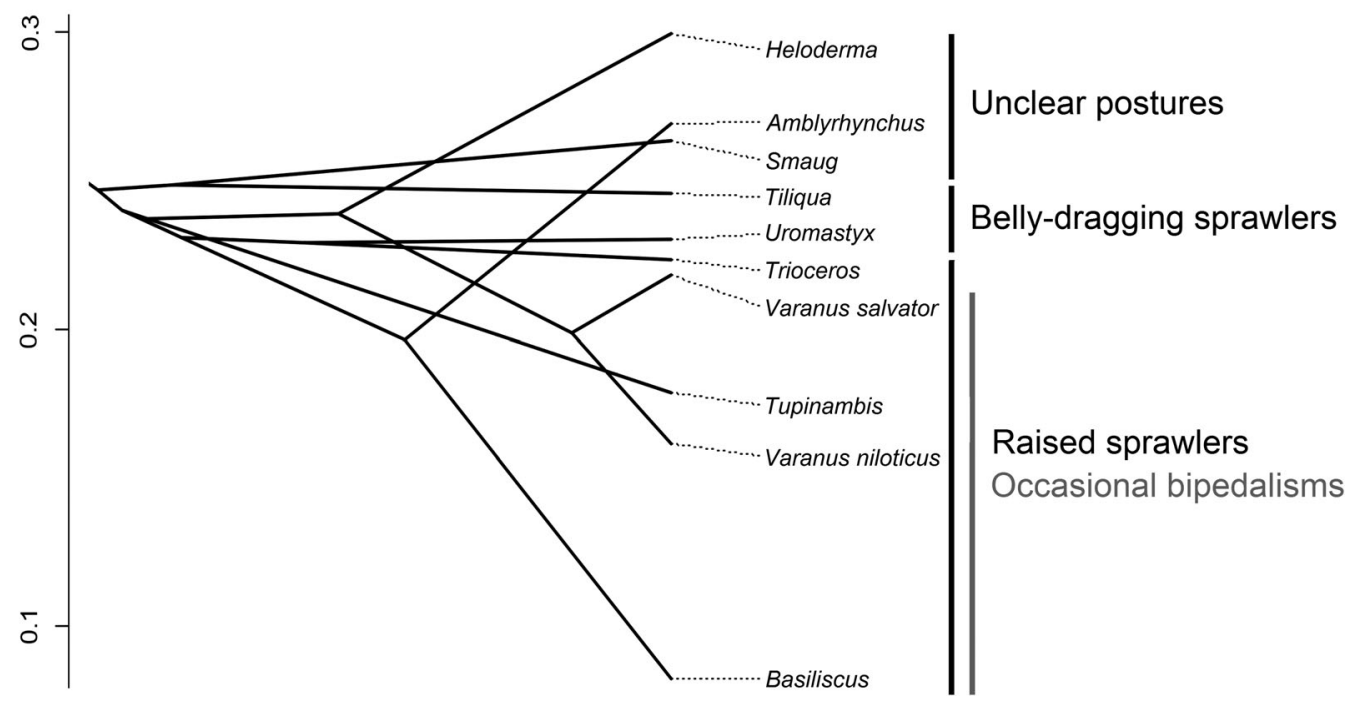

FIGURE 3 Phenogram of squamates defined by the BV/TV parameter. Locomotor postures are indicated on the right part

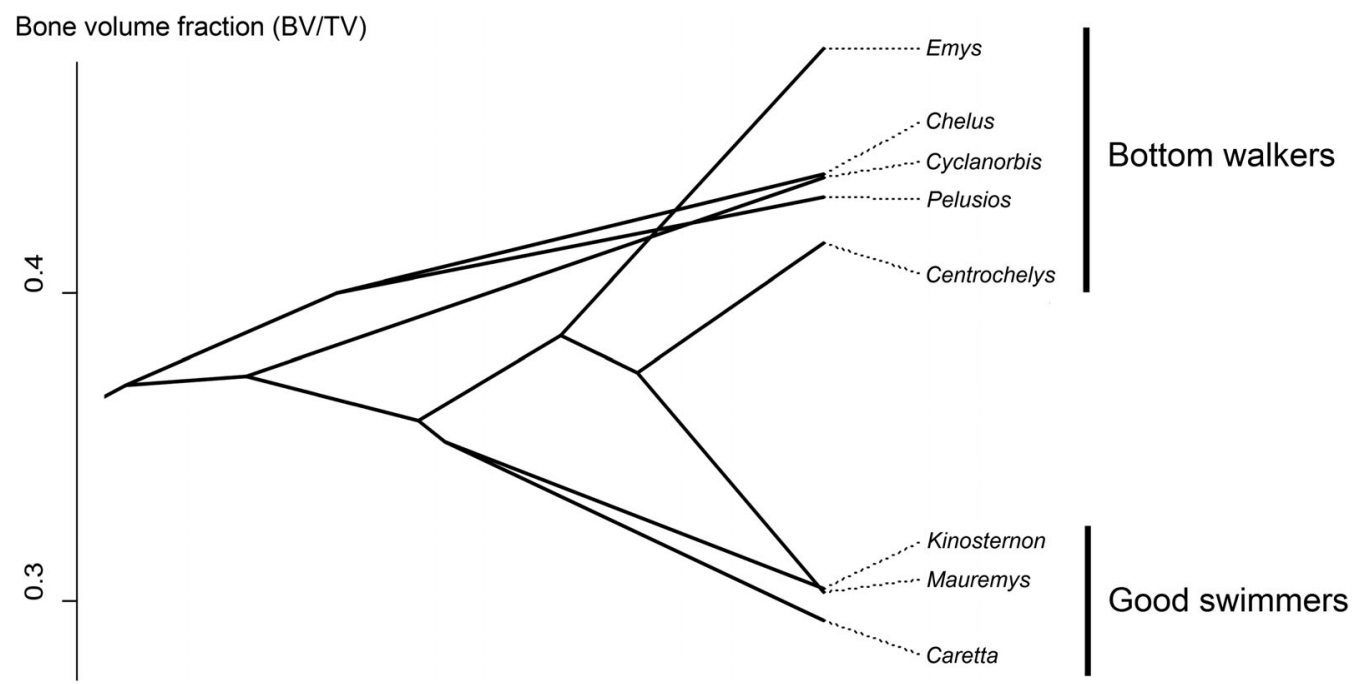

FIGURE 4 Phenogram of turtles defined by the BV/TV parameter. Locomotor postures are indicated on the right part

include only two or three specimens. To avoid lifestyles overlap in the morphological spaces and to increase the discriminating power of LDAs, we reduced the number of categories by gathering them in the last LDAs. In a fifth LDA, we used the eight variables, but we gathered the aquatic and amphibious lifestyles in a "water" category, while we gathered the three other lifestyles in a "ground" category. In a sixth LDA, we used three lifestyle categories: aquatic, amphibious and "ground" (the latter grouping the same three lifestyles). We also performed a phylogenetic Flexible Discriminant Analysis (pFDA; Motani \& Schmitz, 2011) with the "mda" package (Hastie, Tibshirani, \& Buja, 1994) to take into account the phylogeny, but this analysis did not give an improved discrimination of lifestyles as the best discrimination was obtained with a Pagel's lambda equals to zero.
To test our hypotheses on relationships between trabecular anisotropy and lifestyles, we performed additional statistical analyses, where we compared DA according to lifestyles. We do not need to compare scDA, because $p$-value of the linear regression of DA against TV (both log-transformed) is not significant $\left(R^{2}=.1537, p\right.$ value $=.087$ ). In the first comparison, all specimens were included. In the second comparison, specimens for which the corresponding VOI comprised less than 50 trabeculae were excluded. Indeed, calculating the degree of anisotropy from a VOI containing few trabeculae is not really reliable. Thus, by using a histogram on the Connectivity parameter, we chose to determine the lower limit to 50 trabeculae (We cannot determine this limit from Tb.N or Conn.D, which are average numbers of trabeculae). In the last comparisons, we also compared VOls with more than 50 trabeculae but independently in 
TAB LE 6 Allometry in the proximal humeral metaphysis. Trabecular parameters scaling against TV (Total volume) for all reptiles, only squamates and only turtles. The two variables were log-transformed. $a_{\text {iso }}$ represents the expected scaling exponent under isometry, $a_{\mathrm{obs}}$ the observed scaling exponent, $\mathrm{Cl} 95 \%$ represents the confidence intervals to $95 \%$ of the observed slope $\left(a_{\mathrm{obs}}\right)$ and Allo, the corresponding allometry (-for negative allometry, 0 for isometry and + for positive allometry)

\begin{tabular}{|c|c|c|c|c|c|c|c|c|c|c|}
\hline Parameters & $a_{\text {iso }}$ & \multicolumn{3}{|l|}{ All } & \multicolumn{3}{|l|}{ Squamata } & \multicolumn{3}{|l|}{ Testudines } \\
\hline Av.Br.Len & 0.33 & 0.1796 & $0.1482 ; 0.2109$ & - & 0.1691 & $0.1119 ; 0.2264$ & - & 0.1935 & $0.1348 ; 0.2521$ & - \\
\hline Tb.Th & 0.33 & 0.2031 & $0.1601 ; 0.2460$ & - & 0.1637 & $0.0767 ; 0.2506$ & - & 0.1985 & $0.1351 ; 0.2618$ & - \\
\hline Tb.Sp & 0.33 & 0.1363 & $0.0776 ; 0.1951$ & - & 0.1514 & $0.0666 ; 0.2362$ & - & 0.1839 & $0.1660 ; 0.2018$ & - \\
\hline $\mathrm{BS} / \mathrm{TV}$ & -0.33 & -0.335 & $-0.5091 ;-0.1609$ & 0 & -0.4104 & $-0.8267 ; 0.0058$ & 0 & -0.4503 & $-0.6214 ;-0.2792$ & 0 \\
\hline Conn.D & -1 & -0.3436 & $-0.5046 ;-0.1826$ & + & -0.2892 & $-0.4639 ;-0.1145$ & + & -0.5066 & $-0.6742 ;-0.3390$ & + \\
\hline DA & 0 & -0.03439 & $-0.0743 ; 0.0056$ & 0 & 0.0038 & $-0.0829 ; 0.0905$ & 0 & -0.04601 & $-0.0969 ; 0.0049$ & 0 \\
\hline Tb.N & -0.33 & -0.1426 & $-0.2200 ;-0.0652$ & + & -0.1394 & $-0.2871 ; 0.0083$ & + & -0.2064 & $-0.2683 ;-0.1446$ & + \\
\hline
\end{tabular}

Note: See Table 2 for abbreviations of trabecular parameters.

TA B LE 7 List of different linear discriminant analyses (LDA). More details in the material and methods section. Percentages correspond to the correct predictions of the LDAs (i.e., number of correctly classified specimens divided by the number of specimens)

\begin{tabular}{|lclll}
\hline Linear discriminant analyzes & $\begin{array}{l}\text { Raw data } \\
\text { no CV }\end{array}$ & $\begin{array}{l}\text { Raw data } \\
\text { with CV }\end{array}$ & $\begin{array}{l}\text { Size-corrected } \\
\text { data no CV }\end{array}$ & $\begin{array}{l}\text { Size-corrected } \\
\text { data with CV }\end{array}$ \\
\hline Basic & $95 \%$ & $45 \%$ & $95 \%$ & $50 \%$ \\
\hline BV/TV removal & $95 \%$ & $40 \%$ & $90 \%$ & $45 \%$ \\
\hline Two correlated variables (BS/TV + Tb.Sp) removal & $95 \%$ & $60 \%$ & $85 \%$ & $95 \%$ \\
\hline On PCA scores & $100 \%$ & $55 \%$ & $95 \%$ & $50 \%$ \\
\hline Two groups: Water and ground & $90 \%$ & $65 \%$ & $75 \%$ & $70 \%$ \\
\hline Three groups: Aquatic, amphibious and ground & $100 \%$ & $70 \%$ & $95 \%$ & \\
\hline
\end{tabular}

Testudines and in Squamata. For all of these comparisons, we performed the following protocol. As involved specimens change for each comparison, we checked the normality of the distribution of DA, the homogeneity of variance and we compared lifestyles with an ANOVA, a Student's t-test or a Kruskal-Wallis rank sum test (see above for test conditions). Before performing Bartlett's test or a comparison test, we removed lifestyles containing only one specimen from the analysis.

\section{3 | RESULTS}

\section{1 | Histomorphometric results}

Within reptiles, on average, climbers have shorter trabeculae than members of others lifestyles (see Tables 2 and 3). On average, aquatic reptiles show thicker and more spaced trabeculae. Depending on Conn.D and Tb.N, on average, trabeculae are more densely packed in amphibious reptiles. On average, amphibious reptiles show a higher $\mathrm{BS} / \mathrm{TV}$ and a higher BV/TV. BV/TV is significantly lower in squamates than in the crocodylian-turtle clade (mean $=0.22$ and 0.39 , respectively; ANOVA: $p$-value $=1.17 \times 10^{-4}$; Tukey's test between Squamata and Testudines: $p$-value $=1.50 \times 10^{-4}$; Tukey's test between Squamata and Crocodylia: $p$-value $=.011$; Tukey's test between Testudines and Crocodylia: $p$-value $=.99$ ). On average, the degree of anisotropy is similar between the lifestyles.

In Squamata, trabeculae of the proximal humeral metaphysis have an average length of $238 \mu \mathrm{m}$, an average thickness of $115 \mu \mathrm{m}$ and an average spacing of $366 \mu \mathrm{m}$ (see Tables 2 and 4). VOls include an average Conn.D of 19 trabeculae $/ \mathrm{mm}^{3}$ and an average Tb.N of 2 trabeculae/mm. The average BS/TV is $2.45 \mathrm{~mm}^{-1}$ and the average DA is 0.66 . In squamates (Figure 3 ), BV/TV shows a wide range of variation (from 0.083 in Basiliscus to 0.3 in Heloderma) and the average $\mathrm{BV} / \mathrm{TV}$ is 0.22

In Testudines, trabeculae of the proximal humeral metaphysis have an average length of $314 \mu \mathrm{m}$, an average thickness of $182 \mu \mathrm{m}$ and an average spacing of $325 \mu \mathrm{m}$ (see Tables 2 and 4). VOls include an average Conn.D of 67 trabeculae/ $\mathrm{mm}^{3}$ and an average Tb.N of $2.80 \mathrm{trabeculae} / \mathrm{mm}$. The average BS/TV is $3.25 \mathrm{~mm}^{-1}$ and the average DA is 0.59. In turtles (Figure 4), BV/TV shows two well-distinct categories (Kruskal-Wallis chi-squared $=5, p$-value $=.02535$ ) and the average $\mathrm{BV} / \mathrm{TV}$ is 0.39 .

\section{2 | Phylogenetic signal}

Pagel's lambda for each parameter are presented in Table 5. A significant phylogenetic signal is present for the parameter "BV/TV" (Pagel's 
$\lambda=0.705 ; p$-value $<.03$, see mapping in Supporting Information, file 4). BV/TV shows a wide variation in squamates (from 0.083 to 0.300 , Figure 3). In contrast, this parameter is separated into two welldistinct categories in turtles (from 0.294 to 0.304 and from 0.416 to 0.479 , Figure 4$)$. Other parameters do not show any significant phylogenetic signal.

\section{3 | Structural scaling of trabeculae}

To test the allometries of trabecular parameters in reptiles (all specimens, only Squamata and only Testudines), we calculated the slope $\left(a_{\text {obs }}\right)$, the confidence intervals to $95 \%$ of the slope, the coefficient of determination $\left(R^{2}\right)$ and $p$-value of the regressions of each trabecular parameter against the size proxy TV (Table 6, Supporting Information, file 5).

Av.Br.Len, Tb.Th, and Tb.Sp show a significant negative allometric scaling in reptiles generally, but also in squamates and turtles. Larger reptiles have shorter, thinner, and more densely packed trabeculae than expected under geometric scaling. Conn.D and Tb.N show a significant positive allometric scaling in reptiles generally, in squamates and in turtles. Larger reptiles have more trabeculae per volume unit than expected under geometric scaling. BS/TV, BV/TV, and DA show no significant allometric scaling in reptiles, squamates, and turtles. Larger reptiles do not have more trabecular bone per unit of volume or more (or less) aligned trabeculae.

\section{4 | Lifestyles}

While the classic LDA allows to accurately separate the different lifestyles (85-100\% of the taxa are closer to the center of gravity of their own lifestyle), using a leave-one-out cross-validation procedure strongly decreases the performance of the discriminant analysis (well-predicted lifestyle: 40-75\%, Table 7, Supporting Information, files 6 and 8). The analysis of residuals rather than raw data does not necessarily give a better discrimination. The removal of the correlated variables (BS/TV and Tb.Sp) enables a better discrimination, contrary to the exclusion of BV/TV (Figure 5). Using the PCA scores for the individuals, a better class-separation is found for the analysis with raw data, but not with size-corrected data. Gathering lifestyles into two groups enables a better discrimination with a LDA using CV (not in the case of a LDA without CV). Gathering lifestyles into three groups (Figure 6) gives a better discrimination (or the same discrimination in the case of a LDA without CV on size-corrected data).

Using CV, the best separation (60\%) of the five lifestyles is maximized in the LDA on the raw data with the removal of two correlated variables (Table 7 and Figure 5). In the Figure 5, morphological spaces of different lifestyles do not overlap. Reducing into three groups of lifestyles, we obtained the highest discrimination of $70 \%$ with CV and no overlaps of the lifestyles (Figure 6).

To summarize all these linear discriminant analyses (Supporting Information, file 6), we have a poor prediction of lifestyles with CV for aquatic (well-predicted lifestyle to $8.33 \%$ ), fossorial (34.6\%) and

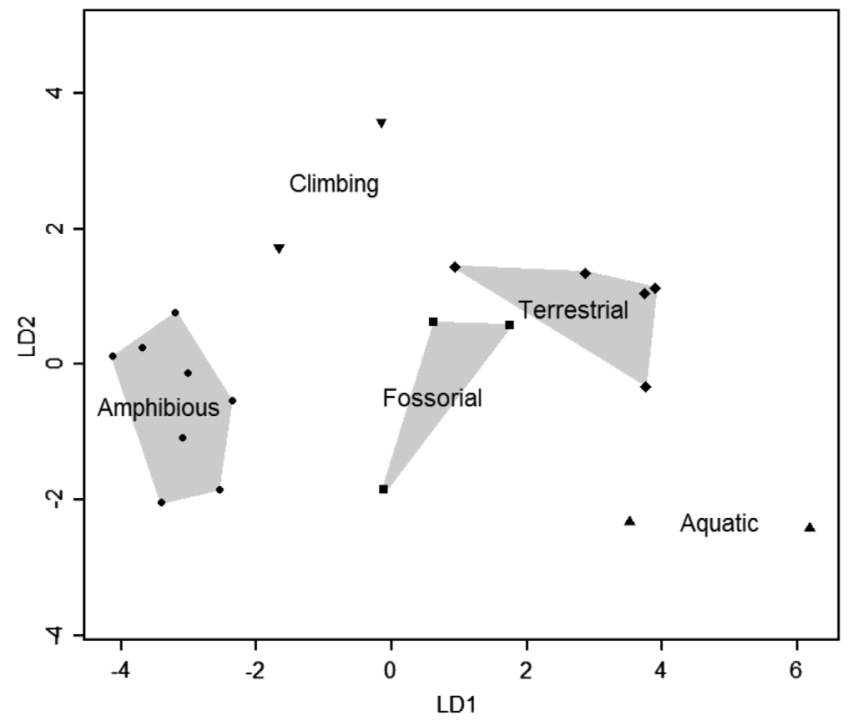

FIGURE 5 LDA on the raw data with removal of two correlated variables (BS/TV and Tb.Sp). The analysis is performed on the five groups of lifestyle: Aquatic (filled triangle point-up), amphibious (filled circle), climbing (filled triangle point-down), fossorial (filled square), and terrestrial (filled diamond)

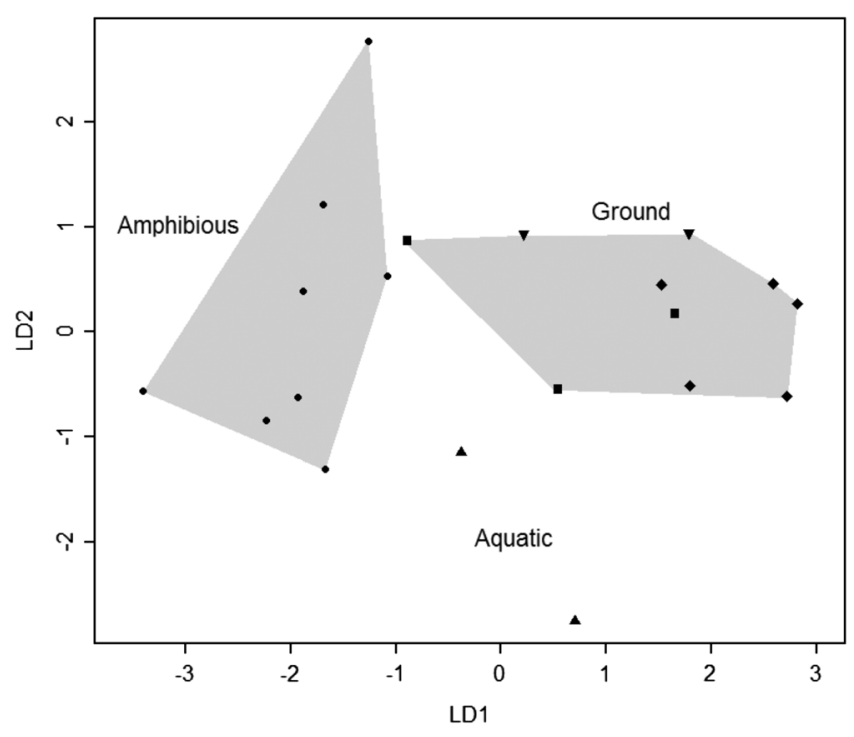

FIGURE 6 LDA on the size-corrected data. The analysis is performed on three lifestyle groups: Aquatic (filled triangle point-up), amphibious (filled circle) and a ground category, which brings together climbing (filled triangle point-down), fossorial (filled square) and terrestrial (filled diamond) lifestyles. The categories corresponding to five-lifestyle scheme (see text) are nevertheless indicated

climbing lifestyles (25\%) and a well-predicted lifestyle in amphibious (79.17\%) and terrestrial lifestyles (66.67\%). Specimens from lifestyles with too few specimens failed to be correctly recognized. Among them, turtles that are not amphibious (Centrochelys, Caretta, Chelus) led to the worst predictions (less than 17\%). The amphibious group with specimens from all main clades is generally subject to good prediction (79.17\%). 
For the comparison of the DA, the ANOVA suggests that there is no significant differences among the lifestyles (Shapiro-Wilk test: $W=0.95501, \quad p$-value $=.4495 ; \quad$ Bartlett's test: $K^{2}=2.1955$, $p$-value $=.6998 ;$ ANOVA: $p$-value $=.999)$. The same conclusion is reached when specimens for which VOIs with less than 50 trabeculae and lifestyles with less than two specimens are excluded (ShapiroWilk test: $W=0.93941, p$-value $=.4108$; Bartlett's test: $K^{2}=1.0333$, $p$-value $=.5965 ;$ ANOVA: $p$-value $=.925$ ). Amphibious specimens show the widest range of variation of DA (from 0.448 to 0.841 ); aquatic specimens have two different values of DA (0.444 and 0.779 ), while the fossorial specimen shows a low DA (0.445); terrestrial specimens have an intermediate DA (from 0.497 to 0.699). For the comparison between DA in Testudines, there is no significant difference between the amphibious and aquatic lifestyles (Shapiro-Wilk test: $\mathrm{W}=0.93398, p$-value $=.553 ;$ Bartlett's test: $K^{2}=5.4335, p$-value $=$ .01975 ; Kruskal-Wallis chi-squared: $t=0, p$-value $=1$ ). Aquatics turtles have two distant values (0.444 and 0.779). Values of DA are intermediate with a limited range in amphibious turtles (from 0.574 to 0.662), but higher than the one of the fossorial Centrochelys (0.445). No test could be performed to compare DA in squamates according to the lifestyles due to a small number of included taxa. Nevertheless, the amphibious Amblyrhynchus shows a higher DA value (0.841) than the terrestrial squamates (from 0.497 to 0.699 ).

\section{4 | DISCUSSION}

\section{1 | Phylogenetic signal}

$\mathrm{BV} / \mathrm{TV}$ is the only trabecular parameter that yields a significant Pagel's lambda $(0.705, p$-value $=.003)$, and it is significantly lower in squamates than in the crocodylian-turtle clade. We propose a physiological explanation related to the limb bone extremities about this phenomenon. Turtles and crocodylians develop cartilaginous limb bone extremities without secondary ossification centers (Haines, 1942). In contrast, squamates show secondary ossification centers, which strengthen the limb bone extremities (Haines, 1942).

In squamates, the wide range of BV/TV variation could be linked to the various locomotor postures (Figure 3). Squamates with the lowest BV/TV values (Basiliscus, Tupinambis and Varanus) are able to practice occasional bipedalism. Squamates that use a "raised" sprawling posture (Trioceros, Varanus, Tupinambis and Basiliscus) have low BV/TV values (0.083-0.224). Uromastyx and Tiliqua, with higher BV/TV values (0.231 and 0.246 respectively) show a "belly-dragging" sprawling posture. The three other squamates (Smaug, Heloderma, and Amblyrhynchus) have unclear locomotor postures. Smaug has a high $\mathrm{BV} / \mathrm{TV}$ value (0.264): it can raise itself off the ground by extending its legs during display (Ruddock, 2000), but this posture could be only practiced during this behavior. The sampled specimen of Heloderma has the highest BV/TV value and both sprawling postures seem to be used depending on the individuals. Amblyrhynchus has a high BV/TV value (0.27), which might be associated with the high compactness values especially found in its fore limb (Hugi \& Sánchez-Villagra, 2012). A higher compactness in fore limb bones counteracts lung buoyancy and facilitates diving and long-lasting underwater stays (de Ricqlès \& de Buffrénil, 2001; Hugi \& Sánchez-Villagra, 2012).

In contrast, BV/TV shows two well-distinct categories in turtles (Figure 4). Turtles with lowest BV/TV values (0.294-0.304) have high swimming abilities (Caretta, Kinosternon, and Mauremys). A significant reduction of body mass would improve locomotor performance of aquatic animals, especially their acceleration abilities and maneuverability (de Ricqlès \& de Buffrénil, 2001). Turtles with highest BV/TV values (0.416-0.479) walk on land (Centrochelys) or at the bottom of lakes (Pelusios, Cyclanorbis, Chelus, and Emys). As in the marine iguana Amblyrhynchus, heavier bones may act as ballast and allow the animal to stay immersed on the bottom (de Ricqlès \& de Buffrénil, 2001).

\section{2 | Structural scaling of trabeculae}

Allometric scaling of trabecular architecture has been analyzed in different bones (femur, humerus, lumbar, and thoracic vertebrae) in various taxa of mammals and birds. Thus, we could compare the observed scaling $\left(a_{\text {obs }}\right)$ of the regression between different trabecular parameters and their size proxies (which is always a length or the body mass) from others studies with an expected scaling under isometry $\left(a_{\text {iso }}\right)$.

Average branch length (Av.Br.Len) scales with a significant negative allometry in squamates and in turtles. This parameter has rarely been used in other studies focused on allometries to our knowledge, but it was significantly correlated to body size in the fore limb epiphyses of extant xenarthrans (Amson et al., 2017).

Trabecular thickness (Tb.Th) and spacing (Tb.Sp) scales with a significant negative allometry in squamates and in turtles. This same significant allometry was also widely found in mammals (Barak, Lieberman, \& Hublin, 2013; Cotter, Simpson, Latimer, \& Hernandez, 2009; Doube et al., 2011; Fajardo et al., 2013; Ryan \& Shaw, 2013) and in birds (Doube et al., 2011).

Bone surface density (BS/TV) scales with isometry in squamates and in turtles, while it has shown positive allometry in mammalian and avian femora (see Table 1 in Doube et al., 2011).

Bone volume fraction (BV/TV) shows no dependence with size in squamates and in turtles. BV/TV was also reported to be independent of body size in mammals, through various sampled bones in a wide variety of taxa (Barak, Lieberman, \& Hublin, 2013), but also in more restricted samplings: in thoracic vertebrae of hominoids (Cotter et al., 2009) or in fore limb epiphyses of xenarthrans (Amson et al., 2017). However, other analyses have found that BV/TV had a positive allometry in the femoral epiphyses of mammals and birds (Doube et al., 2011), in the lumbar vertebrae of strepsirrhine primates (Fajardo et al., 2013), in the humeral and femoral heads of primates (Ryan \& Shaw, 2013) and in the femoral heads of sciuromorphs (Mielke et al., 2018). For BV/TV, isometry or positive allometry do not seem to be associated to a particular bone (both present in vertebrae and limbs bones) or clade (both present throughout mammals), but this parameter might be correlated to other characteristics, such as locomotor postures.

Connectivity density (Conn.D) scales with significant positive allometry in squamates and in turtles. This parameter has also shown 
a same significant allometry in mammals (Barak, Lieberman, \& Hublin, 2013; Doube et al., 2011; Fajardo et al., 2013; Ryan \& Shaw, 2013) and in birds (Doube et al., 2011).

The degree of anisotropy (DA) shows no correlation with size in squamates and in turtles, like in the thoracic vertebrae of hominoids (Cotter et al., 2009). In mammals, DA has shown a negative allometry in epiphyses: in the femora of many clades of mammals (see Table 1 in Doube et al., 2011), in the femoral heads of sciuromorphs (Mielke et al., 2018), in the humeral and femoral heads of primates (Ryan \& Shaw, 2013) and in various VOls of mammals (Barak, Lieberman, \& Hublin, 2013). In birds, DA has shown a negative allometry in the femoral condyle, but a positive allometry in the femoral head (Doube et al., 2011). It is unexpected that DA shows a negative allometry in mammals and avian epiphyses, but no correlation with size in nonavian reptiles metaphyses (this could be linked to the different location of the sampled VOI).

Trabecular number (Tb.N) scales with a positive allometry in squamates and in turtles. This parameter has shown a significant positive allometry in mammals (Barak, Lieberman, \& Hublin, 2013; Cotter et al., 2009; Fajardo et al., 2013; Ryan \& Shaw, 2013).

To summarize, within amniotes, BS/TV, BV/TV, and DA have different allometric (or isometric) scalings depending on the VOI location and the sampled clade. In contrast, the positive allometries (Tb.Th, Tb.Sp) and negative allometries (Conn.D, Tb.N) seems to be relatively conserved in mammals, birds, turtles and squamates. We can suppose that these allometric scalings, previously emphasized in mammals and birds, could be generalized to amniotes. Additional studies in other clades like crocodylians and sphenodontians, but also lissamphibians, will be necessary to confirm this statement.

\section{3 | Lifestyles}

The exclusion of BV/TV (which showed a significant phylogenetic signal) for the parameters included in the LDA leads to a decrease of the discriminating power. Within reptiles, BV/TV seems to be a complex trabecular parameter correlated to the phylogeny, but also to lifestyles and locomotor postures (see above). Conversely, BS/TV and Tb.Sp, which are highly correlated to other parameters, show no link to the phylogeny or the lifestyle. In our study, the coordinates of the individuals from principal component axes does not give better discrimination. Gathering lifestyles into two or three groups is a good compromise to obtain a clearer separation (65-75\%) because the probability of misidentifications of $\mathrm{CV}$ decreases. Nevertheless, on the raw data, the analysis with three groups of lifestyles yields a better discrimination than the analysis with two groups. These results are encouraging: morphological spaces of lifestyle rarely overlapped, even if predictions with CV reached $70 \%$. Nevertheless, it seems important to notice that more specimens should be added in the poorly represented lifestyles, especially aquatic and climber. As highlighted in this study, considering multiple architectural parameters together can prove more informative in elucidating lifestyles than by studying a single variable in isolation. This result had also been found by other studies in the case of locomotor behavior in primates (Amson \& Nyakatura, 2018; Hébert, Lebrun, \& Marivaux, 2012; Ryan \& Shaw, 2012; Scherf, Harvati, \& Hublin, 2013).

\subsection{Degree of anisotropy versus lifestyle}

We compared the degree of anisotropy according to the lifestyle. Comparing all the specimens, there is no clear distinction of lifestyles. Indeed, the small size of some squamates implies that the corresponding VOI only comprise a few trabeculae (as in Smaug or Basiliscus). Large specimens would give more reliable results in the analysis of the degree of anisotropy.

Using only specimens with more than 50 trabeculae, we obtain a poor separation of lifestyles. Amphibious specimens show a wide range of variation of DA, because this group consists of three distantly related clades. Indeed, this variation is lower in turtles. Aquatic specimens tend to have distant values of DA, and the fossorial specimen a low DA. However, the small sample size makes any further interpretation difficult to draw.

In turtles, the degree of anisotropy tends to be higher in amphibious taxa than in the fossorial Centrochelys. In large squamates, there is a similar gradient with a higher degree of anisotropy in the amphibious Amblyrhynchus than in terrestrial relatives. We hypothesized that terrestrial tetrapods may have a more defined orientation of their trabeculae than aquatic ones, and that amphibious taxa may have an intermediate state. We can refute this hypothesis as our results based on the proximal metaphysis of the humerus of reptiles tend to show the opposite trend for amphibious and terrestrial taxa. However, for aquatic species, we cannot validate or refute our hypothesis and we need more sampled taxa. We propose that this opposite trend could be explained by the location of the VOI extraction, in the middle of the metaphysis. Whether this gradient of trabecular orientation according to the lifestyle is also present at other locations, such as epiphyses or in other bones remains to be tested. In the radial head of xenarthrans, the degree of anisotropy of trabeculae have also showed another gradient: highest values in fully terrestrial and fossorial armadillos, intermediate values in intermediate anteaters and lowest values in fully arboreal sloths (Amson et al., 2017).

\section{5 | Potential limitations}

Some possible limitations should be noted for this study. First, the scan resolution can induce possible bias because some trabecular parameters are sensitive to this acquisition parameter (Isaksson et al., 2011; Sode et al., 2008). For instance, the relative resolution (i.e., mean trabecular thickness/voxel size, see Sode et al., 2008, Kivell et al., 2011) ranges between 1.53 in Chelus and 20.53 in Centrochelys. Conversely, we only could sample one specimen per species and hence did not take into account the intraspecific variation, which has been highlighted in several trabecular parameters, like the degree of anisotropy (Ryan \& Ketcham, 2005). However, the addition of additional specimens will certainly improve the models. Moreover, we scanned the left or right humerus depending on the availability, which 
could be another bias, but we do not think that the results are influenced by the humerus laterality.

Moreover, the placement of volumes of interest may create a bias in the results. We extracted VOIs from the proximal metaphysis, at the location where the pectoral process was the most developed, in order to compare homologous areas between the sampled specimens and to avoid the presence of epiphyseal plates in squamates. The regions directly adjacent to the articular condyles, directly exposed to mechanical loadings, may show stronger lifestyle discrimination. However, in our case, these regions could not be sampled in squamates because of their epiphyseal plates.

The choice of a VOI of maximal size, rather than a scaled VOI, can be also bias the trabecular parameters. However, most of the studied parameters (bone volume fraction, trabecular thickness, number, and spacing) were not influenced by VOI size in other studies (Kivell et al., 2011; Lazenby et al., 2011). In contrast, degree of anisotropy could be more sensitive to $\mathrm{VOI}$ size change, when studying a more heterogeneous structure (Kivell et al., 2011; Lazenby et al., 2011). Furthermore, VOls are not scaled and do not have the same size for all specimens: the extracted volume can be small in some specimens (e.g., $0.433 \mathrm{~mm}^{3}$ in Kinosternon) or large in other ones (e.g., 1,268.667 $\mathrm{mm}^{3}$ in Caretta). Moreover, a larger pectoral process, related to the anatomy or the lifestyle of a small animal, could give a larger VOI and potentially change the allometric scaling of trabecular parameters. Our choice of VOI selection could skew the results, but to our knowledge, it was the only procedure that facilitated sampling of enough trabeculae from small specimens (of which the metaphyses include only few trabeculae).

Using TV as a proxy for body size could be another limitation. We could not use other size proxies like humeral length or minimal diaphyseal circumference, because the sampled specimens have a wide variety of morphologies.

Finally, we also tried to take into account potential phylogenetic effects thanks to the use of pFDA and the measure of Pagel's lambda for each trabecular parameter. However, the fact that our sampling is uneven could involve a strong phylogenetic bias.

\section{6 | Conclusion}

This study is the first to present 3D-trabecular architecture of the humeral proximal metaphysis in various clades of extant reptiles (Crocodylia, Squamata, and Testudines) through a $\mu$ CT-scan dataset. Thanks to the analyses of trabecular parameters, we are able to highlight allometries, most of which were also found in mammals and birds. These parameters do not show a significant phylogenetic signal, except for the bone volume fraction (BV/TV), which can be strongly correlated to the epiphysation degree. The various linear discriminant analyses show that lifestyle discrimination seems possible. We also find a tendency for the degree of anisotropy to differ between terrestrial and amphibious lifestyles, but further analyses including greater sampling will be required to confirm this statement.

Moreover, this study provides other useful data to perform further trabecular anisotropy analyses concerned with lifestyle signals. It is preferable to focus at the rank order rather than larger clades, where the anisotropic signals could be mixed. Furthermore, larger specimens should be studied in order to recover a reliable degree of anisotropy. It would not be surprising if other studies also recover a gradient in the trabecular anisotropy values among lifestyles (rather than a clear discrimination), because lifestyles often describe a continuum from strictly terrestrial to strictly aquatic ones. In the same way that some studies were able to predict locomotor behavior of extinct primates (Ryan \& Ketcham, 2002b), studies on relationships between lifestyle and trabecular architecture could help to determine accurately the lifestyle of other extinct tetrapods (see e.g., Amson \& Nyakatura, 2018).

\section{ACKNOWLEDGMENTS}

We thank the PhD program "Interface pour le Vivant (IPV)" for research funding, the German Research Council (DFG AM 517/1-1) which funded Eli Amson and the Action Thématique du Muséum (ATM) for CT-scan funding. We also acknowledge Maïté Adam, Marta Bellato and Patricia Wils (UMS 2700 OMSI, AST-RX) for the CTscanning procedure. We also want to thank Natacha Catz and Audrey Pofis for their invaluable help in this project. We want to thank Salvador Bailon for the access to the collection of comparative anatomy and Michel Laurin for the loan of the humerus of Amblyrhynchus cristatus. Finally, we thank the two anonymous reviewers for their particularly useful comments.

\section{AUTHOR CONTRIBUTIONS}

MP, QG and DG conceived the study. MP, DG and QG conceived the methodology for image processing. MP acquired and analyzed the raw data, and drafted the manuscript. EA drafted the Fiji script. All authors performed the analyses. All authors reviewed the manuscript and gave their final approval.

\section{ORCID}

Martial Plasse (D) https://orcid.org/0000-0002-8397-4948

\section{REFERENCES}

Adams, D. C., \& Collyer, M. L. (2018). Phylogenetic ANOVA: Group-clade aggregation, biological challenges, and a refined permutation procedure. Evolution, 72(6), 1204-1215.

Amson, E., Arnold, P., van Heteren, A. H., Canoville, A., \& Nyakatura, J. A. (2017). Trabecular architecture in the forelimb epiphyses of extant xenarthrans (Mammalia). Frontiers in Zoology, 14(1), 52.

Amson, E. \& Nyakatura, J.A., (2018). Palaeobiological inferences based on long bone epiphyseal and diaphyseal structure - The forelimb of xenarthrans (Mammalia). bioRxiv, 318121, ver. 5. DOI: https://doi.org/ $10.1101 / 318121$

Barak, M. M., Lieberman, D. E., \& Hublin, J. J. (2011). A Wolff in sheep's clothing: Trabecular bone adaptation in response to changes in joint loading orientation. Bone, 49(6), 1141-1151. 
Barak, M. M., Lieberman, D. E., \& Hublin, J. J. (2013). Of mice, rats and men: Trabecular bone architecture in mammals scales to body mass with negative allometry. Journal of Structural Biology, 183(2), 123-131.

Barak, M. M., Lieberman, D. E., Raichlen, D., Pontzer, H., Warrener, A. G., \& Hublin, J. J. (2013). Trabecular evidence for a human-like gait in Australopithecus africanus. PLoS One, 8(11), e77687.

Bartholomew, G. A., Bennett, A. F., \& Dawson, W. R. (1976). Swimming, diving and lactate production of the marine iguana, Amblyrhynchus cristatus. Copeia, 709-720.

Ben-Zvi, Y., Reznikov, N., Shahar, R., \& Weiner, S. (2017). 3D architecture of trabecular bone in the pig mandible and femur: Inter-trabecular angle distributions. Frontiers in Materials, 4, 29.

Bertolero, A. \& Busack, S.D. (2017). Mauremys leprosa (Schoepff in Schweigger 1812) - Mediterranean pond turtle, Spanish terrapin, Mediterranean stripe-necked terrapin. In: Rhodin, A.G.J., Iverson, J.B., van Dijk, P.P., Buhlmann, K.A., Pritchard, P.C.H., and Mittermeier, R.A. (Eds.). Conservation biology of freshwater turtles and tortoises: A compilation project of the IUCN/SSC tortoise and freshwater turtle specialist group. Lunenburg, MA, USA: Chelonian Research Monographs 5(10): 102.1-19.

Bishop, P. J., Hocknull, S. A., Clemente, C. J., Hutchinson, J. R., Farke, A. A., Beck, B. R., ... Lloyd, D. G. (2018). Cancellous bone and theropod dinosaur locomotion. Part I-An examination of cancellous bone architecture in the hindlimb bones of theropods. PeerJ, 6, e5778.

Bishop, P. J., Walmsley, C. W., Phillips, M. J., Quayle, M. R., Boisvert, C. A., \& McHenry, C. R. (2015). Oldest pathology in a tetrapod bone illuminates the origin of terrestrial vertebrates. PLoS One, 10 (5), e0125723.

Bogert, C. M., \& Martín del Campo, R. (1956). The gila monster and its allies: the relationships, habits, and behavior of the lizards of the family Helodermatidae. Bulletin of the AMNH, 109, article 1.

Branch, W. R. (1998). Field guide to the snakes and other reptiles of southern Africa (3rd ed.). Cape Town: Ralph Curtis Publishing.

Campbell, J. A. (1998). Amphibians and reptiles of northern Guatemala, the Yucatán, and Belize (Vol. 4). Norman: University of Oklahoma Press.

Carlson, K. J., Lublinsky, S., \& Judex, S. (2008). Do different locomotor modes during growth modulate trabecular architecture in the murine hind limb? Integrative and Comparative Biology, 48(3), 385-393.

Chirio, L., \& LeBreton, M. (2007). Atlas des Reptiles du Cameroun. Muséum National d'Histoire Naturelle (p. 688). Paris: IRD.

Ciliberti, A. (2011). Le varan du Nil (Varanus niloticus) indicateur de la pollution des zones humides d'Afrique sub-saharienne (p. 158). Lyon: Doctoral dissertation, Université de Lyon.

Clarac, F., De Buffrénil, V., Brochu, C., \& Cubo, J. (2017). The evolution of bone ornamentation in Pseudosuchia: Morphological constraints versus ecological adaptation. Biological Journal of the Linnean Society, 121 (2), 395-408.

Cotter, M. M., Simpson, S. W., Latimer, B. M., \& Hernandez, C. J. (2009). Trabecular microarchitecture of hominoid thoracic vertebrae. The Anatomical Record, 292(8), 1098-1106.

Cowin, S. C. (1998). The false premise of Wolff's law. Forma, 12(3), 247-262.

Cunningham, C. A., \& Black, S. M. (2009). Anticipating bipedalism: Trabecular organization in the newborn ilium. Journal of Anatomy, 214(6), 817-829.

Davenport, J., Munks, S. A., \& Oxford, P. J. (1984). A comparison of the swimming of marine and freshwater turtles. Proceedings of the Royal Society of London B: Biological Sciences, 220(1221), 447-475.

Diagne, T., Luiselli, L., Trape, J.-F., Rödel, M.-O., Baker, P.J., Chirio, L., Petrozzi, F. \& Segniagbeto, G. (2016). Cyclanorbis senegalensis. The IUCN Red List of Threatened Species 2016: e.T6005A96447114. http://dx.doi.org/10.2305/IUCN.UK.2016-2.RLTS.T6005A96447114. en. Downloaded on 10 May 2019.

Doube, M., Kłosowski, M. M., Arganda-Carreras, I., Cordelières, F. P., Dougherty, R. P., Jackson, J. S., ... Shefelbine, S. J. (2010). BoneJ: Free and extensible bone image analysis in ImageJ. Bone, 47(6), 1076-1079.

Doube, M., Kłosowski, M. M., Wiktorowicz-Conroy, A. M., Hutchinson, J. R., \& Shefelbine, S. J. (2011). Trabecular bone scales allometrically in mammals and birds. Proceedings of the Royal Society of London B: Biological Sciences, 278, 3067-3073.

Duméril, A. M. C., \& Bibron, G. (1835). Erpétologie Générale ou Histoire Naturelle Complète des Reptiles. Tome Second. Librairie Encyclopédique de Roret, Paris, ii, 2, 13-24.

Fajardo, R. J., Desilva, J. M., Manoharan, R. K., Schmitz, J. E., Maclatchy, L. M., \& Bouxsein, M. L. (2013). Lumbar vertebral body bone microstructural scaling in small to medium-sized strepsirhines. The Anatomical Record, 296(2), 210-226.

Fajardo, R. J., Hernandez, E., \& O'Connor, P. M. (2007). Postcranial skeletal pneumaticity: A case study in the use of quantitative microCT to assess vertebral structure in birds. Journal of Anatomy, 211(1), 138-147.

Fajardo, R. J., \& Müller, R. (2001). Three-dimensional analysis of nonhuman primate trabecular architecture using micro-computed tomography. American Journal of Physical Anthropology: The Official Publication of the American Association of Physical Anthropologists, 115(4), 327-336.

Fajardo, R. J., Müller, R., Ketcham, R. A., \& Colbert, M. (2007). Nonhuman anthropoid primate femoral neck trabecular architecture and its relationship to locomotor mode. The Anatomical Record, 290(4), 422-436.

Ficetola, G. F., Padoa-Schioppa, E., Monti, A., Massa, R., Bernardi, F. D., \& Bottoni, L. (2004). The importance of aquatic and terrestrial habitat for the European pond turtle (Emys orbicularis): Implications for conservation planning and management. Canadian Journal of Zoology, 82(11), 1704-1712.

Gatesy, S. M. (1991). Hind limb movements of the American alligator (Alligator mississippiensis) and postural grades. Journal of Zoology, 224(4), 577-588.

Gerhard, F. A., Webster, D. J., Van Lenthe, G. H., \& Müller, R. (2009). In silico biology of bone modelling and remodelling: Adaptation. Philosophical Transactions of the Royal Society of London A: Mathematical, Physical and Engineering Sciences, 367(1895), 2011-2030.

Gleeson, T. T. (1979). Foraging and transport costs in the Galapagos marine iguana, Amblyrhynchus cristatus. Physiological zoology, 52(4), 549-557.

Haines, R. W. (1942). The evolution of epiphyses and of endochondral bone. Biological Reviews, 17(4), 267-292.

Hastie, T., Tibshirani, R., \& Buja, A. (1994). Flexible discriminant analysis by optimal scoring. Journal of the American Statistical Association, 89(428), 1255-1270.

Hébert, D., Lebrun, R., \& Marivaux, L. (2012). Comparative threedimensional structure of the trabecular bone in the talus of primates and its relationship to ankle joint loads generated during locomotion. The Anatomical Record: Advances in Integrative Anatomy and Evolutionary Biology, 295(12), 2069-2088.

Hugi, J., \& Sánchez-Villagra, M. R. (2012). Life history and skeletal adaptations in the Galapagos marine iguana (Amblyrhynchus cristatus) as reconstructed with bone histological data-A comparative study of iguanines. Journal of Herpetology, 46, 312-324.

Huiskes, R., Ruimerman, R., Van Lenthe, G. H., \& Janssen, J. D. (2000). Effects of mechanical forces on maintenance and adaptation of form in trabecular bone. Nature, 405(6787), 704-706.

Isaksson, H., Töyräs, J., Hakulinen, M., Aula, A. S., Tamminen, I., Julkunen, P., ... Jurvelin, J. S. (2011). Structural parameters of normal and osteoporotic human trabecular bone are affected differently by microCT image resolution. Osteoporosis International, 22(1), 167-177.

Kivell, T. L. (2016). A review of trabecular bone functional adaptation: What have we learned from trabecular analyses in extant hominoids and what can we apply to fossils? Journal of Anatomy, 228(4), 569-594. 
Kivell, T. L., Skinner, M. M., Lazenby, R., \& Hublin, J. J. (2011). Methodological considerations for analyzing trabecular architecture: An example from the primate hand. Journal of Anatomy, 218(2), 209-225.

Lambers, F. M., Koch, K., Kuhn, G., Ruffoni, D., Weigt, C., Schulte, F. A., \& Müller, R. (2013). Trabecular bone adapts to long-term cyclic loading by increasing stiffness and normalization of dynamic morphometric rates. Bone, 55(2), 325-334.

Lazenby, R. A., Skinner, M. M., Kivell, T. L., \& Hublin, J. J. (2011). Scaling VOI size in $3 \mathrm{D} \mu \mathrm{CT}$ studies of trabecular bone: A test of the oversampling hypothesis. American Journal of Physical Anthropology, 144(2), 196-203.

Lê, S., Josse, J., \& Husson, F. (2008). FactoMineR: An R package for multivariate analysis. Journal of Statistical Software, 25(1), 1-18.

Legler, J. M., \& Vogt, R. C. (2013). The Turtles of Mexico: Land and Freshwater Forms. Berkeley, California, USA: University of California Press.

Limpus, C. J., Miller, J. D., Paramenter, C. J., Reimer, D., McLachlan, N., \& Webb, R. (1992). Migration of green (Chelonia mydas) and loggerhead (Caretta caretta) turtles to and from eastern Australian rookeries. Wildlife Research, 19(3), 347-357.

Marchand, C., Chen, H., Buschmann, M. D., \& Hoemann, C. D. (2011). Standardized three-dimensional volumes of interest with adapted surfaces for more precise subchondral bone analyses by micro-computed tomography. Tissue Engineering Part C: Methods, 17(4), 475-484.

Martin, R. B., Burr, D. B., Sharkey, N. A., \& Fyhrie, D. P. (2015). Growth, modeling and remodeling of bone. In Skeletal tissue mechanics (pp. 95-173). New York: Springer, New York.

van der Meulen, M. C., Morgan, T. G., Yang, X., Baldini, T. H., Myers, E. R., Wright, T. M., \& Bostrom, M. P. (2006). Cancellous bone adaptation to in vivo loading in a rabbit model. Bone, 38(6), 871-877.

Mielke, M., Wölfer, J., Arnold, P., van Heteren, A. H., Amson, E., \& Nyakatura, J. A. (2018). Trabecular architecture in the sciuromorph femoral head: Allometry and functional adaptation. Zoological Letters, 4(1), 10.

Mittra, E., Rubin, C., \& Qin, Y. X. (2005). Interrelationship of trabecular mechanical and microstructural properties in sheep trabecular bone. Journal of Biomechanics, 38(6), 1229-1237.

Motani, R., \& Schmitz, L. (2011). Phylogenetic versus functional signals in the evolution of form-function relationships in terrestrial vision. Evolution, 65(8), 2245-2257.

Nyakatura, J. A., Andrada, E., Curth, S., \& Fischer, M. S. (2014). Bridging "Romer's gap": Limb mechanics of an extant belly-dragging lizard inform debate on tetrapod locomotion during the early carboniferous. Evolutionary Biology, 41(2), 175-190.

Pagel, M. (1999). Inferring the historical patterns of biological evolution. Nature, 401(6756), 877-884.

Pierce, S. E., Clack, J. A., \& Hutchinson, J. R. (2012). Three-dimensional limb joint mobility in the early tetrapod Ichthyostega. Nature, 486 (7404), 523-526.

Pontzer, H., Lieberman, D. E., Momin, E., Devlin, M. J., Polk, J. D., Hallgrimsson, B., \& Cooper, D. M. L. (2006). Trabecular bone in the bird knee responds with high sensitivity to changes in load orientation. Journal of Experimental Biology, 209(1), 57-65.

R Core Team (2013). R: A language and environment for statistical computing. R Foundation for Statistical Computing, Vienna, Austria. Retrieved from http://www.R-project.org/

Ramesh, M., \& Sankaran, R. (2013). Natural History Observations on the Indian Spiny-tailed Lizard Uromastyx hardwickii in the Thar Desert. In Faunal Heritage of Rajasthan, India (pp. 295-310). New York, NY: Springer.

Reilly, S. M., \& Elias, J. A. (1998). Locomotion in Alligator mississippiensis: Kinematic effects of speed and posture and their relevance to the sprawling-to-erect paradigm. Journal of Experimental Biology, 201(18), 2559-2574.

Revell, L. J. (2012). Phytools: An R package for phylogenetic comparative biology (and other things). Methods in Ecology and Evolution, 3(2), 217-223. de Ricqlès, A., \& de Buffrénil, V. (2001). Bone histology, heterochronies and the return of tetrapods to life in water: Where are we? In Secondary adaptation of Tetrapods to life in water (pp. 289-310). Germany: Verlag Dr. Friedrich Pfeil, München.

Roux, W. (1885). Beitrage zur Morphologie der funktionellen Anpassung. Archives of Anatomy and Physiology, 9, 120-185.

Ruddock, L. (2000). Social structure of the lizard, Cordylus giganteus (Doctoral dissertation). Stellenbosch University, Stellenbosch.

Russell, A. P., \& Bels, V. (2001). Biomechanics and kinematics of limbbased locomotion in lizards: Review, synthesis and prospectus. Comparative Biochemistry and Physiology Part A: Molecular \& Integrative Physiology, 131(1), 89-112.

Ryan, T. M., \& Ketcham, R. A. (2002a). The three-dimensional structure of trabecular bone in the femoral head of strepsirrhine primates. Journal of Human Evolution, 43(1), 1-26.

Ryan, T. M., \& Ketcham, R. A. (2002b). Femoral head trabecular bone structure in two omomyid primates. Journal of Human Evolution, 43(2), 241-263.

Ryan, T. M., \& Ketcham, R. A. (2005). Angular orientation of trabecular bone in the femoral head and its relationship to hip joint loads in leaping primates. Journal of Morphology, 265(3), 249-263.

Ryan, T. M., \& Shaw, C. N. (2012). Unique suites of trabecular bone features characterize locomotor behavior in human and non-human anthropoid primates. PLoS One, 7(7), e41037.

Ryan, T. M., \& Shaw, C. N. (2013). Trabecular bone microstructure scales allometrically in the primate humerus and femur. Proceedings of the Royal Society of London B: Biological Sciences, 280(1758), 20130172.

Ryan, T. M., \& Shaw, C. N. (2014). Gracility of the modern Homo sapiens skeleton is the result of decreased biomechanical loading. Proceedings of the National Academy of Sciences, 112(2), 372-377.

Ryan, T. M., \& Walker, A. (2010). Trabecular bone structure in the humeral and femoral heads of anthropoid primates. The Anatomical Record, 293 (4), 719-729.

Scherf, H., Harvati, K., \& Hublin, J. J. (2013). A comparison of proximal humeral cancellous bone of great apes and humans. Journal of Human Evolution, 65(1), 29-38.

Schindelin, J., Arganda-Carreras, I., Frise, E., Kaynig, V., Longair, M., Pietzsch, T., ... Cardona, A. (2012). Fiji: An open-source platform for biological-image analysis. Nature Methods, 9(7), 676-682.

Schuett, G. W., Reiserer, R. S., \& Earley, R. L. (2009). The evolution of bipedal postures in varanoid lizards. Biological Journal of the Linnean Society, 97(3), 652-663.

Shaffer, H. B., McCartney-Melstad, E., Near, T. J., Mount, G. G., \& Spinks, P. Q. (2017). Phylogenomic analyses of 539 highly informative loci dates a fully resolved time tree for the major clades of living turtles (Testudines). Molecular Phylogenetics and Evolution, 115, 7-15.

Snyder, R. C. (1949). Bipedal locomotion of the lizard Basiliscus basiliscus. Copeia, 1949(2), 129-137.

Sode, M., Burghardt, A. J., Nissenson, R. A., \& Majumdar, S. (2008). Resolution dependence of the non-metric trabecular structure indices. Bone, 42(4), 728-736.

Stearns, B. C. (1989). The captive status of the African spurred tortoise Geochelone sulcata: Recent developments. International Zoo Yearbook, 28(1), 87-98.

Trillmich, K. G., \& Trillmich, F. (1986). Foraging strategies of the marine iguana, Amblyrhynchus cristatus. Behavioral Ecology and Sociobiology, 18(4), 259-266.

Urban, E. K. (1965). Quantitative study of locomotion in teiid lizards. Animal Behaviour, 13(4), 513-529.

Venables, W. N., \& Ripley, B. D. (2002). Modern applied statistics with S (4th ed.). New York: Springer.

Vitt, L. J., \& Caldwell, J. P. (2014). Herpetology: An introductory biology of amphibians and reptiles. Norman, Oklahoma: University of Oklahoma Press. 
Volpato, V., Viola, T. B., Nakatsukasa, M., Bondioli, L., \& Macchiarelli, R. (2008). Textural characteristics of the iliac-femoral trabecular pattern in a bipedally trained Japanese macaque. Primates, 49(1), 16-25.

Wilms, T., \& Böhme, W. (2007). Review of the taxonomy of the spinytailed lizards of Arabia (Reptilia: Agamidae: Leiolepidinae: Uromastyx). Fauna of Arabia, 23, 435-468.

Wilson, S. K., \& Swan, G. (2013). A complete guide to reptiles of Australia. Australia: New Holland.

Wyneken, J., Godfrey, M. H., \& Bels, V. (2008). Biology of Turtles. Bota Raton, FL, USA: CRC Press.

Zheng, Y., \& Wiens, J. J. (2016). Combining phylogenomic and supermatrix approaches, and a time-calibrated phylogeny for squamate reptiles (lizards and snakes) based on 52 genes and 4162 species. Molecular Phylogenetics and Evolution, 94, 537-547.

\section{SUPPORTING INFORMATION}

Additional supporting information may be found online in the Supporting Information section at the end of this article. 